\title{
Multiple cell interactions are required for fate specification during male spicule development in Caenorhabditis elegans
}

\author{
Helen M. Chamberlin and Paul W. Sternberg \\ Howard Hughes Medical Institute and Division of Biology, California Institute of Technology, Pasadena, CA 91125, USA
}

\section{SUMMARY}

The B blast cell divides postembryonically in C. elegans males to produce 47 progeny that include all of the cells of the copulatory spicules. During the early development of the $B$ lineage, the anterior daughter of B, B.a, generates eight cells. These cells migrate to form four pairs of cells that flank the developing cloaca (ventral, dorsal, and two identical lateral pairs). For each pair, the more anterior cell produces a distinct lineage ('anterior fate') from the posterior cell ('posterior fate'). For the ventral and dorsal pairs, either cell can migrate to the anterior position and produce the anterior lineage, and the other cell migrates posterior and produces the posterior lineage (Sulston and Horvitz, 1977, Dev. Biol. 56, 110-156). The migration is variable, although the resultant fate pattern is invariant. In the two lateral pairs, both the migration and fate pattern are invariant. Using a laser microbeam to selectively ablate neighboring cells we have found that the cells of the lateral pair also respond to positional cues. For all four pairs other male-specific blast cells provide extracellular cues. In general, $F$ and $U$ promote anterior fates, $Y$ promotes some posterior fates, and the B.a progeny promote posterior fates. Several of these cues are redundant. By ablating combinations of cells we have deduced how these signals may act in concert to specify the fates of the B.a progeny. We propose that fate specification in these pairs depends on three general classes of extracellular cues: positional cues, modulators of positional cues, and lateral signals. The B lineage thus provides an opportunity to study with single cell resolution the integration of multiple intercellular signals.

Key words: C. elegans, cell lineage, cell interactions, cell fate specification, redundancy, pattern formation

\section{INTRODUCTION}

The fate of a cell can be specified by information provided by the cell's precursors and by signals from the cell's neighbors. The experimental study of cell lineage (patterns of cell division and their relationship to cell fate) can provide clues about these mechanisms of fate specification and their interrelationship. The ability to visualize cell nuclei and their divisions in C. elegans, combined with the reproducibility of the lineage among animals, has allowed the complete description of the normal cell division pattern and the differentiated terminal fates (Sulston and Horvitz, 1977; Sulston et al., 1980, 1983). The cell lineage in C. elegans is essentially invariant. However, because the extracellular environment for most developing cells is as constant as the ancestry, the correlation of cell division and fate does not indicate that fate specification is completely autonomous. Indeed, cell interactions likely play an important role in cell fate specification. For example, the lineage includes several instances of cells that have the potential to adopt more than one fate (Sulston and Horvitz, 1977; Kimble and Hirsh, 1979; Sulston et al., 1983). In addition, embryonic blast cell rearrangement (Priess and Thomson, 1987; Wood, 1991) and isolation experiments (Schierenberg, 1987; Goldstein, 1992), as well as embryonic (Bowerman et al., 1992) and postembryonic cell ablation experiments (Sulston and White, 1980; Kimble, 1981; Chisholm and Hodgkin, 1989) have identified instances of cell interactions that specify cell fate. The invariant cell lineage, rather than indicating a limited repertoire of fate specification mechanisms, offers a reproducible background to study the interplay of autonomous and conditional mechanisms.

To study the components of fate specification, we have focused our attention on the postembryonic lineage of the male B cell. The B cell is one of four male-specific blast cells ( $\mathrm{B}, \mathrm{U}, \mathrm{F}$ and $\mathrm{Y}$ ) that divide in males, but not in hermaphrodites, and produce some of the cells of the specialized mating structures of the male tail. The male B cell, for instance, produces all of the cells of the copulatory spicules (Fig. 1). The B lineage (Fig. 2) includes examples of autonomous as well as conditional fate specification. For example, the B cell undergoes asymmetric cytokinesis in its first division, which has been studied as a possible example of autonomous fate specification (Sternberg and Horvitz, 1988). Later in the lineage, two pairs of B progeny cells exhibit natural variation (Sulston and Horvitz, 1977). In each pair, one cell adopts the anterior position and fate, and the other cell the posterior position and fate. Although which cell adopts the anterior position varies from one animal to the next, the resultant pattern of anterior and 

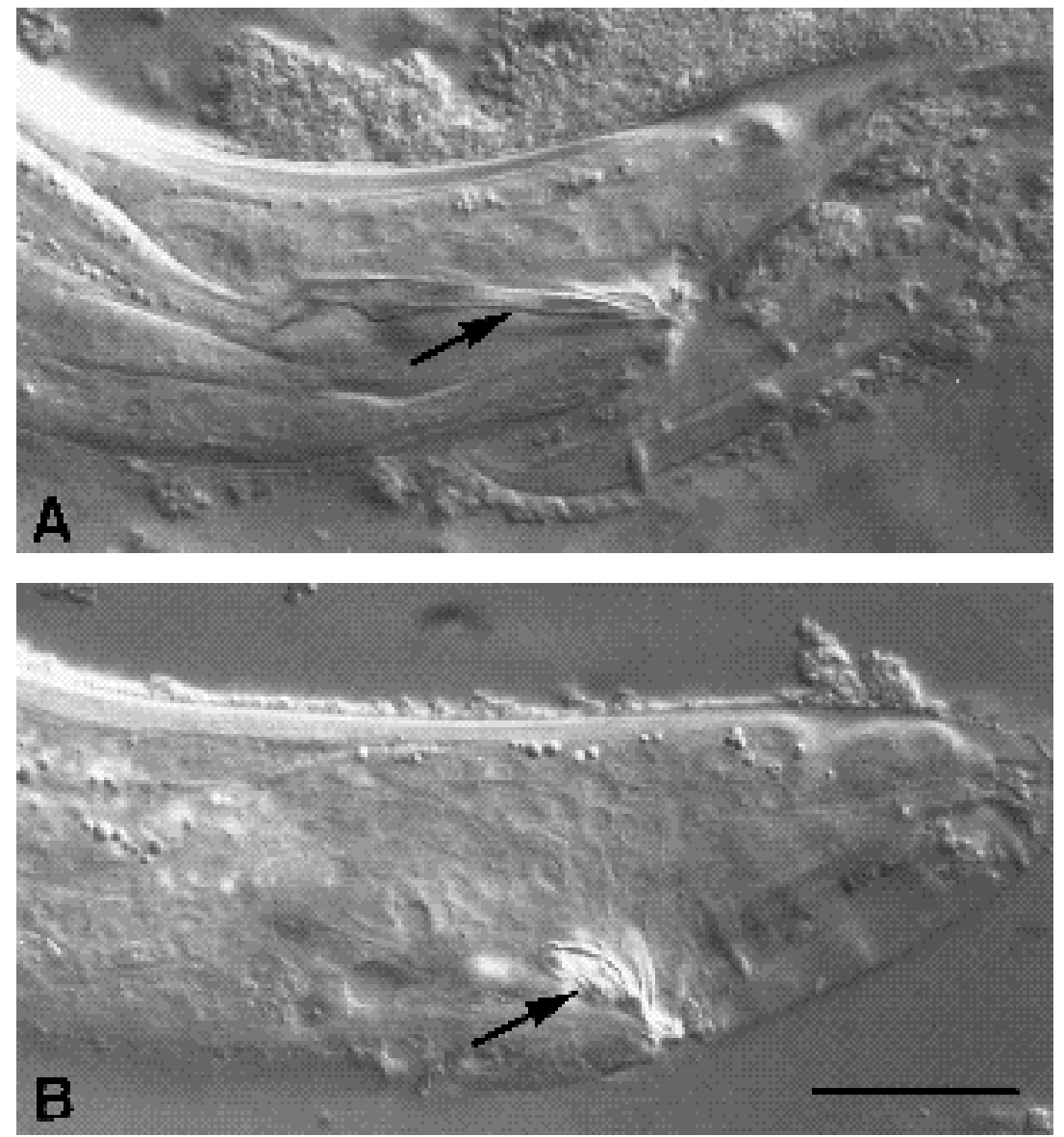

Fig. 1. Comparison of the adult male spicule in intact (A) and $\mathrm{F}^{-} \mathrm{U}^{-}$(B) animals. Arrows point to the left spicule. Nomarski photomicrographs, left lateral view (anterior left, ventral down). (A) In intact animals the spicules are long and straight. (B) $\mathrm{In} \mathrm{F}^{-} \mathrm{U}^{-}$ animals the spicules are short and crumpled due to disruption of the cell lineage that produces the spicule cells. Scale bar, $20 \mu \mathrm{m}$. posterior fates is always the same. Since the fate reflects the cell's position rather than its ancestry, this represents an example where extracellular cues likely play a role in fate specification.

In this study we use cell ablation to identify cells that provide specific extracellular cues. Ablation experiments also allow us to characterize the interaction of these cues, and to deduce their roles in fate specification. We focus on four pairs of B progeny cells that represent three distinct pair types. We have identified multiple extracellular cues that specify fate choice in each pair. These fall into three general classes (see Fig. 17): positional cues (such as inducers and inhibitors), modulators of positional cues (active or passive), and lateral signals. We present evidence that multiple extracellular cues may act in parallel, as well as in series, to specify cell fate(s). Having established extracellular components of fate and the developmental potentials of these cells, we also consider the interplay of autonomous and extracellular cues in producing the fates of the B cell lineage.

\section{MATERIALS AND METHODS}

\section{Strains}

Methods for culturing and handling $C$. elegans have been described by Brenner (1974) and Sulston and Hodgkin (1988). The strain CB1490 him-5(e1490) provides a convenient source of normal males, and we established it as the 'wild type' background for all ablations. The mutation him-5(e1490) increases loss and nondisjunction of the $\mathrm{X}$ chromosome, with little effect on the five autosomes (Hodgkin et al., 1979). Consequently, him-5 mutant hermaphrodites (XX) segregate about $40 \%$ male (XO) self progeny.

\section{Cell nomenclature}

Nomenclature follows the standard of Sulston and Horvitz (1977). The proper names for the B.a progeny at the 10 cell stage (Fig. $3 \mathrm{E}$ and Legend) are B.a(1/r)aa, B.a(1/r)ap, B.a(1/r)pa, and B.a(l/r)pp. Collectively, we refer to the cells as $\mathrm{B} \cdot \mathrm{a}(\mathrm{l} / \mathrm{r}) \mathrm{xx}$, where $\mathrm{x}$ refers to both daughter cells. We use $(1 / \mathrm{r})$ to indicate both the left and the right members of a pair. When we refer to a single set in the text we have removed the common prefix and shortened the names to aa, ap, pa, and pp. The intention is to increase readability, hopefully without the confusion often associated with the renaming of cells. We consider this simply a shorthand way of referring to the cells, and use the full, proper name in any instance that the shortened name might prove ambiguous. In general, aa, etc, refers to two cells - both the left and the right - except where explicitly noted.

\section{Cell lineage and laser ablation}

Cell nuclei divisions were directly observed in live animals under Nomarski optics as described by Sulston and Horvitz (1977). Except where noted, the lineage of all B progeny cells was followed in each animal to completion. We have used the cell lineage - the axes, timing, and number of cell divisions - as an assay of cell fate. Therefore, although most animals were observed from the first divisions of the B.a(l/r)xx cells (early-mid L3 larval stage) 

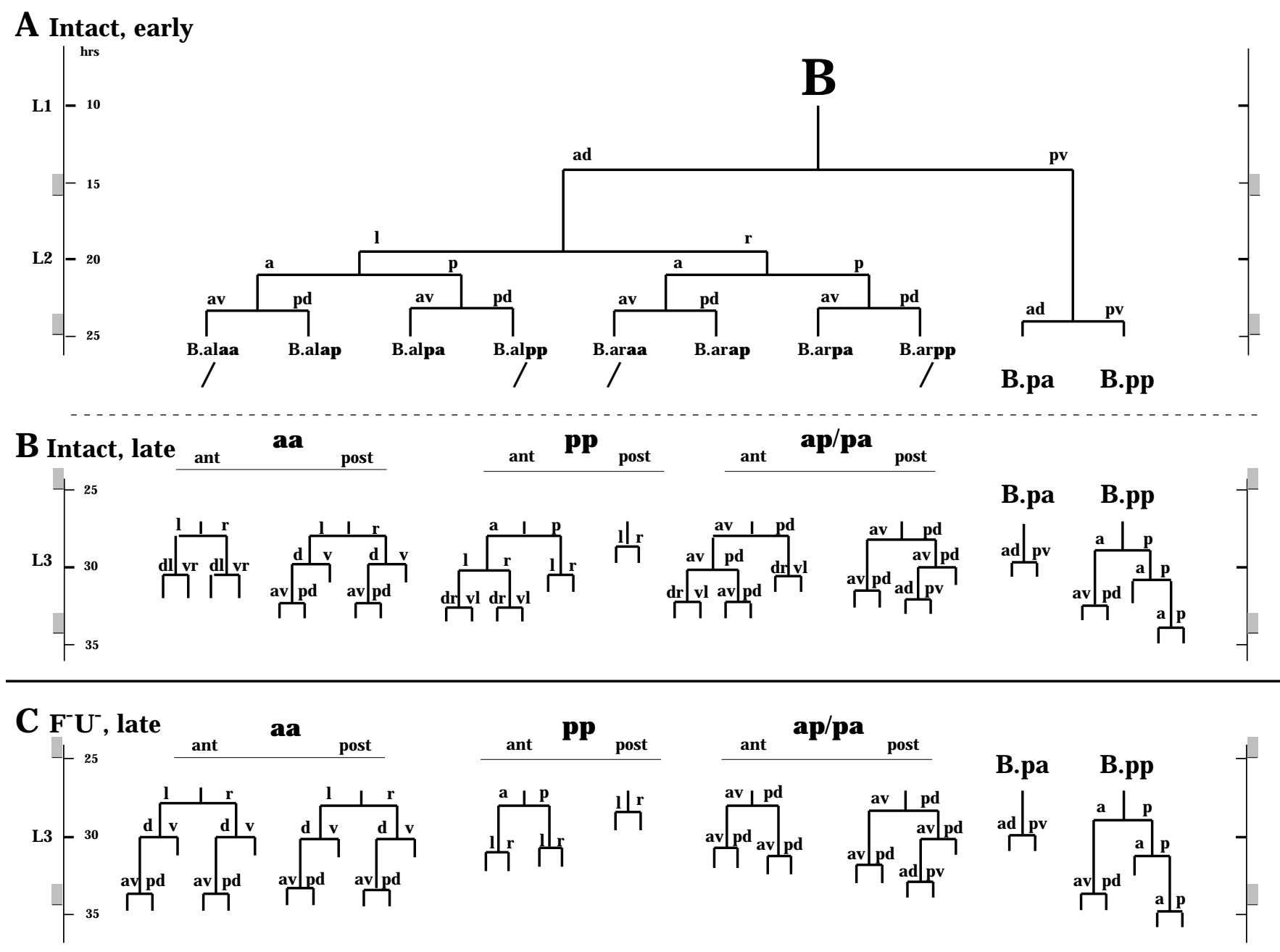

Fig. 2. B lineage in intact and ablated animals. Division axes are shown: anterior (a), posterior (p), left (l), right (r), dorsal (d), ventral (v). (A) Early divisions in the intact male. Lineage chart constructed from lineage and observation of anatomy of intact him-5(e1490) males. (B) Late divisions in the intact male. Lineage chart constructed from unperturbed lineages observed in B.p $\mathrm{p}^{-}, \mathrm{F}^{-}$, or $\mathrm{U}^{-}$animals. (C) Late divisions in $\mathrm{F}^{-} \mathrm{U}^{-}$animal. Lineage chart constructed from $\mathrm{F}^{-} \mathrm{U}^{-}$animal 128 (see Table 1B.1). Note that lineages of presumptive $\alpha, \gamma$, and $\varepsilon$ cells (anterior cells; ant) are disrupted. Early B divisions are normal in ablated animals. Division axes and time scale are standardized to Sulston et al. (1980). Cell deaths and terminal fates are not shown. The terminal fates are indicated in Table 8 . The $\alpha, \beta, \delta$ and $\zeta$ lineage patterns are all distinct. $\gamma$ and $\varepsilon$ lineages both produce 6 progeny in a $2+4$ pattern ( 2 progeny from one daughter, 4 from the other), but they differ in division axes. $\beta$ lineages produce 6 progeny in a $3+3$ pattern.

through L3 molt, cells generally were not followed to the time when programmed cell deaths are observed in intact animals. Since the fates of B.p progeny were not disrupted by any ablation, we have used the timing of B.p divisions to correlate abnormal to normal lineages. Outside of the B progeny, the divisions of P11.p, P10.p and P9.p provide additional non-disrupted timepoints. Although complete lineages were not obtained for these cells, we generally followed at least two division cycles in these cells.

Laser killing of cells was performed by the method of Sulston and White (1980), using the laser microbeam system and procedure of Avery and Horvitz (1987) and Sternberg (1988), except that the laserbeam was passed through a circular variable attenuator (gift of Newport Corporation), and animals were anesthetized on pads of $5 \%$ agar in water, containing $5 \mu \mathrm{M}$ (rather than 10 $\mu \mathrm{M})$ sodium azide. In general, F, U, and Y.p were ablated at the stage when B had divided to produce two cells (late L1 or early L2 stage). B.a progeny were ablated during mid to late L2 stage, generally soon after the targeted cells were generated. Many ani- mals required ablation of cells at different stages of development. In these cases the animals underwent two to three rounds of anesthetic, surgery, recovery, and development. In all cases, animals that appeared unhealthy following treatment were discarded. The ablation of the targeted cells was confirmed the following day when the animals were prepared for lineage analysis.

For technical reasons, surgeries were performed on one day, and lineages followed the next. At $20^{\circ} \mathrm{C}$ only $5-10$ hours separate the time of surgery and the re-initiation of $\mathrm{B} . \mathrm{a}(\mathrm{l} / \mathrm{r}) \mathrm{xx}$ cell division. Consequently, after a recovery and development period (1-6 hours, depending on the nature of the surgery) animals were shifted from $20^{\circ} \mathrm{C}$ to $10^{\circ} \mathrm{C}$ overnight to slow further development. Such shifts could disrupt temperature-sensitive aspects of the cell interactions or other developmental processes. However, (1) all of the experimental animals were treated the same, so our experiments are internally consistent, (2) normal lineages are observed in many ablation backgrounds (e.g., B.p ${ }^{-}$, see Table 1C.2), and (3) many ablations specifically disrupt a subset of fates, with the remaining fates essentially normal. Because normal lineages are possible, and 
abnormal lineages are specific to certain ablation backgrounds, we believe the temperature shift does not fundamentally affect our results. All lineages were observed at $20^{\circ} \mathrm{C}$.

\section{RESULTS}

\section{Summary of spicule development}

The spicules are a pair of structures that flank the male cloaca (Fig. 1). Electron microscope reconstruction by Sulston et al. (1980) indicate that the two spicules are sensilla covered with a hard, sclerotic cuticle. Each spicule includes two presumptive sensory neurons. Each neuron has a process that runs down the length of the spicule to the tip, where it is open to the environment. The neuronal processes are surrounded by socket and sheath cells, which provide structure and support. Each spicule is anchored by extensor and retractor muscles. During copulation the male inserts his spicules into the hermaphrodite vulva, where they anchor the male cloaca at the vulval opening and possibly aid in sperm transfer.

The $\mathrm{B}$ cell divides to produce all of the cells of the spicules. The B cell lineage consists of three distinct stages: early divisions, migration, and late divisions (Figs 2, 3 and 4; original observations of Sulston and Horvitz, 1977; Sulston et al., 1980). The early divisions take place primarily in the second larval stage (L2), and result in 10 progeny. A short range migration of the eight B.a progeny occurs in the late L2 stage. The late round of divisions begin in the mid-L3 stage, ultimately producing 47 progeny. The first division of $\mathrm{B}$ is asymmetric and along an approximately anterior/posterior axis (Figs 3A, 4A). The larger anterior cell (B.a) is the precursor of all cells of the spicules. B.a divides along a left/right axis, establishing the bilateral symmetry of the spicules. This symmetry is broken (during migration) and then re-established (during the late divisions) in the progeny of these cells. B.al and B.ar each divide twice to produce a ring of eight cells, one cell thick (Fig. 3D). These cells then migrate. The medial migration of the two dorsal (pp) and ventral (aa) cells exhibits natural variation. In both cases, either the right or the left cell can adopt the more anterior position, while the other cell adopts the more posterior position. The cell that adopts the anterior position will produce a different lineage than the cell that adopts the posterior position (compare anterior $\alpha$ and $\gamma$ lineages to posterior $\beta$ and $\delta$ lineages in Fig. 2). The other four B.a progeny migrate invariantly. The ap cells adopt the anterior position (one on the left, one on the right), and the pa cells adopt the posterior position. The end result is a ring of cells, two cells thick (Figs 3E, 4B). It is convenient to refer to animals with the $\mathrm{B}$ progeny in this configuration as the ' 10 cell stage,' since in addition to the eight progeny of B.a, B.p has divided once.

The aa and pp pairs represent equivalence groups (Sulston and Horvitz, 1977; Sulston et al., 1980). In general, cells in an equivalence group have equivalent potential, but they adopt different fates after interacting with each other, after receiving positional cues, or both. Because of the variability from animal to animal, one must distinguish between lineal ancestry and fate choice when referring to cells in an equivalence group. Within the aa pair, the fate of the ante-
Side view

A
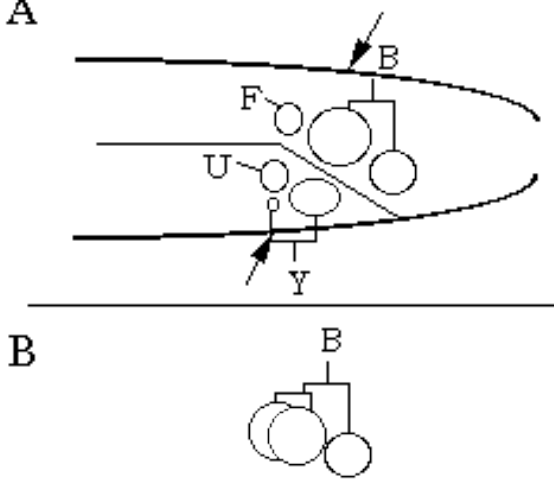

$C$

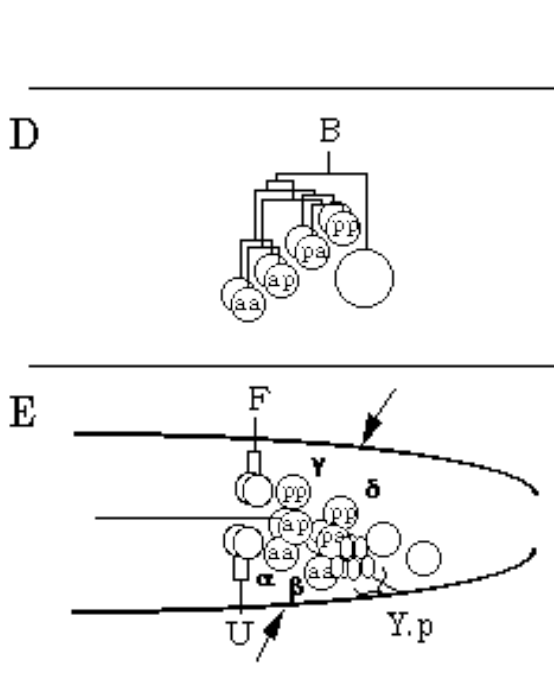

Fig. 3. The early divisions of B. Left lateral view and cross section of B.a at one (A), two (B), four (C), eight (D) cell stage, and after migration (E). Arrows indicate approximate plane of cross section. B.a divides along a left-right axis to initially establish the bilateral symmetry of the spicules (B). B.a produces eight progeny that form a ring of cells, a single cell thick (D). These cells migrate to form a ring of cells, two cells thick (E). It is convenient to refer to animals with the B progeny in this configuration as the ' 10 cell stage' since in addition to the eight progeny of B.a, B.p has divided once. F, U, and Y.p also divide during the early $\mathrm{B}$ divisions. $\mathrm{F}$ and $\mathrm{U}$ lie anterior to $\mathrm{B}$, dorsal and ventral to the rectum, respectively (A). These cells divide once during the early $\mathrm{B}$ lineage, so that when the $\mathrm{B} \cdot \mathrm{a}(\mathrm{l} / \mathrm{r}) \mathrm{xx}$ cells have migrated to their anterior/posterior positions, F.l and F.r lie next to presumptive $\gamma$, and U.l and U.r lie next to presumptive $\alpha$ (E). These cells further divide during the late B divisions (Sulston et al., 1980). Y divides asymmetrically prior to the first division of B, producing a neuron and the Y.p blast cell (A). During the early B lineage, Y.p divides once to establish left/right symmetry. Further divisions result in a cluster of five cells on each side. The position of these clusters is more dorsal and lateral than the original position of $Y(E)$. 

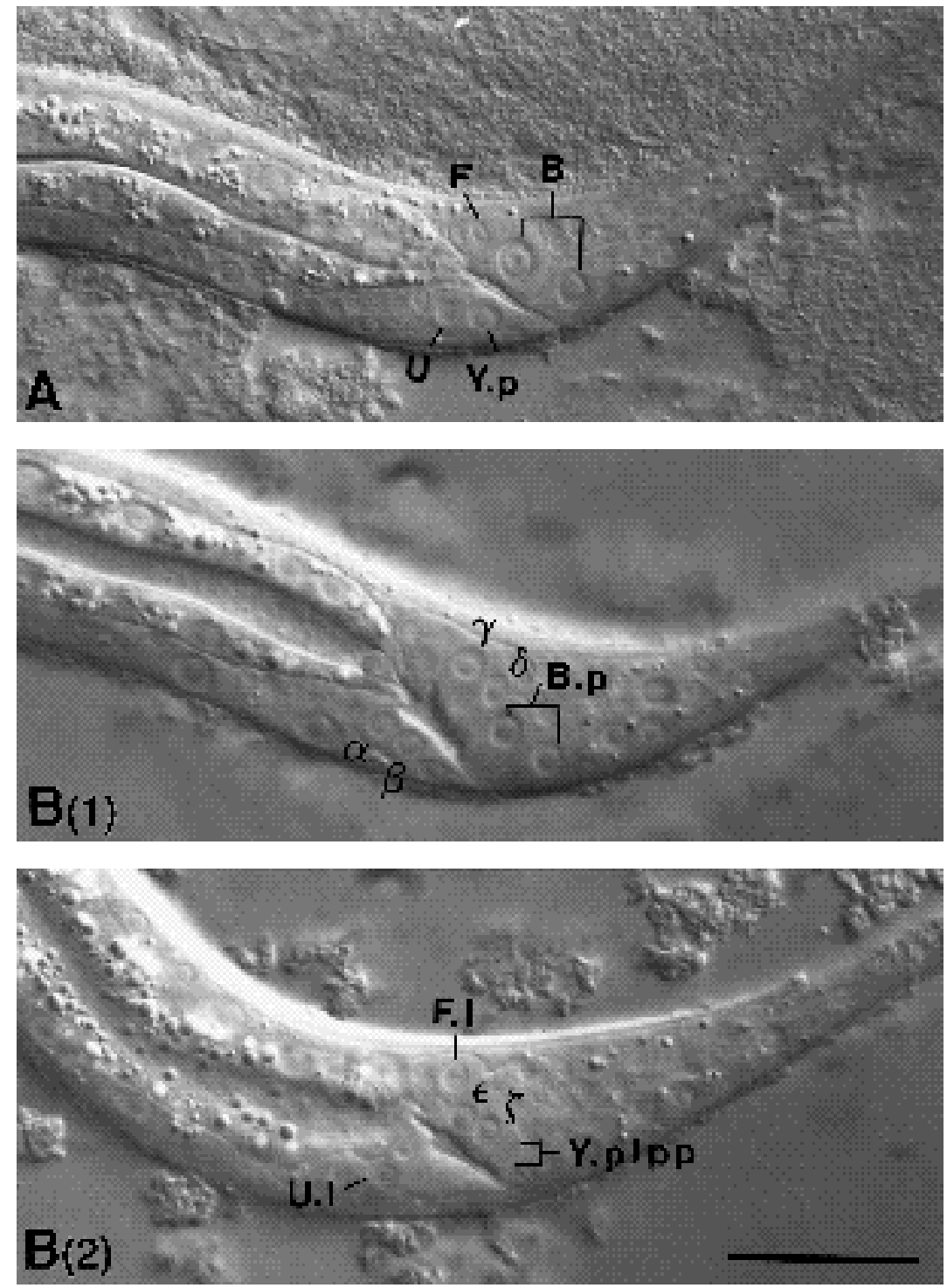

Fig. 4. Nomarski photomicrographs of early divisions of the B cell. (A) Arrangement of male-specific blast cells in the early L2 stage male. $\mathrm{B}$ and $\mathrm{Y}$ have each divided once (compare with Fig. 3A). (B1,2) Arrangement of $\mathrm{B}$ progeny at the 10 cell stage in early L3 male, medial (B.1) and left lateral (B.2) view of same animal. $\mathrm{F}$ and $\mathrm{U}$ have each divided once.

Division of Y.p( $(1 / \mathrm{r}) \mathrm{pp}$ is the final cell division in the Y lineage. The remaining Y.pl progeny are slightly ventral, anterior, and lateral to the dividing Y.plpp cell (compare with Fig. 3E). Scale bar, $20 \mu \mathrm{m}$. rior cell is termed $\alpha$, and the posterior cell, $\beta$. Likewise, the anterior cell in the pp pair is $\gamma$, and the posterior cell, $\delta$ (Sulston and Horvitz, 1977). Sulston and White (1980) showed that after ablation of either the left or right aa cell, the remaining aa cell will migrate to the midline and produce an $\alpha$ lineage. This establishes the $\alpha$ fate as primary $\left(1^{\circ}\right)$ and the $\beta$ fate as secondary $\left(2^{\circ}\right)$. Even if the targeted cell is migrating to the anterior position when it is ablated, the remaining cell will produce an $\alpha$ lineage, indicating either that position promotes the $\alpha$ fate, or that the fate of the aa cell is still flexible after migration is initiated. Similar experiments with the pp cells could not establish $1^{\circ}$ or $2^{\circ}$ fate in the $\gamma / \delta$ pair.

We will show (Section II.B) that the ap and pa cells also respond to positional cues. In intact animals the fates of these cells are invariant. Our experiments indicate that there are distinct anterior and posterior fates, normally associated with the ap and pa cells, respectively. To distinguish between lineal ancestry and fate choice for these cells, we have assigned the Greek letter $\varepsilon$ to the lineage normally associated with the ap cells (the 'anterior' fate), and the letter $\zeta$ to the lineage normally associated with the pa cells (the 'posterior' fate).

For the B.a(l/r)xx cells, lineal heritage, cell position, and fate (subsequent lineage) are distinct characteristics. There are thus three distinct groups of B.a progeny. The aa cells represent one group, the ventral pair. Likewise, the pp cells comprise the dorsal pair. There are two lateral pairs (one left, one right), each comprising one ap and one pa cell. We consider the two laterally symmetrical pairs to be identical. We refer to the ventral, lateral, and dorsal groups as the aa, ap/pa, and pp pairs, respectively. Within each group there is a distinct anterior and a distinct posterior position. For instance, in intact animals the ap cells always adopt the anterior position in each lateral group. Finally, there are six distinct fates $(\alpha, \beta, \gamma, \delta, \varepsilon, \zeta) . \gamma$ indicates the lineage normally associated with the anterior cell in the dorsal group. Experimentally, however, this lineage is not restricted to the anterior position, although it is restricted to the dorsal group. Since these names represent observed 
lineages as well as conceptual fates, we use the term $\gamma$ lin eage when referring to an observed result (literally, a $\gamma$-like lineage), and $\gamma$ fate when discussing interpretations. We use the term 'presumptive $\gamma$ ' to refer to the cell in the anterior position of the dorsal group, regardless of the lineage.

\section{Interpretation of cell lineage data}

The fate of precursor cells includes the cell lineage (number, timing and axes of divisions) and the terminal differentiated fates of the progeny produced by those divisions. Although both criteria are important to understanding the fate of a precursor cell, we have focused on the first. In the $\mathrm{B}$ lineage, the precise differentiated fates of the progeny are difficult to assess because (1) many of the precursors produce a similar set of differentiated cell types, (2) nuclear morphology (often used to identify neurons) is difficult to establish unambiguously due to the dense packing of cells in the tail, and (3) we currently lack suitable molecular markers that distinguish among the fates. In other analyses of postembryonic development in $C$. elegans, cell lineage has proved to be an accurate indicator of fate choice (e.g., Horvitz et al., 1983; Kenyon, 1986; Sternberg and Horvitz, 1986). In addition, we have observed transformation of terminal differentiation (cell death) in two animals where pa produced $\varepsilon$ lineages (data not shown). In this example, the transformation of cell lineage correlates with the transformation of differentiated cell fate. Thus, we believe that the number, timing, and axes of cell divisions generally reflect fate choice for a postembryonic blast cell. We cannot rule out the hypothesis that the terminal fates are distinct from the cell lineage, or that fate transformations are from $\mathrm{B}$ progeny to another cell type. However, we have limited our discussion to transformations within B cell fates. For simplicity, we initially hypothesize that the choice of $\alpha$ versus $\beta, \gamma$ versus $\delta$, and $\varepsilon$ versus $\zeta$ fates is specified in the B.a( $1 / \mathrm{r}) \mathrm{xx}$ cells. We discuss the validity of these assumptions at the end of each sub-section of Section III.

We often observe full transformation from one fate to another following cell ablation. However, we also observe a variety of abnormal lineages, and we have named the common ones (Fig. 5). A rigorous interpretation of the fate represented by abnormal lineages is sometimes difficult. In these cases we use the number of progeny as an indicator of fate as it is the most objective of cell lineage criteria. In the pp pair, for instance, we refer to the production of more progeny as reflecting an anterior-like $(\gamma)$ state, and the production of fewer progeny a posterior-like $(\delta)$ state. We rely on the criterion of progeny number only in cases where the

\section{A. Common abnormal lineages and normal counterparts}
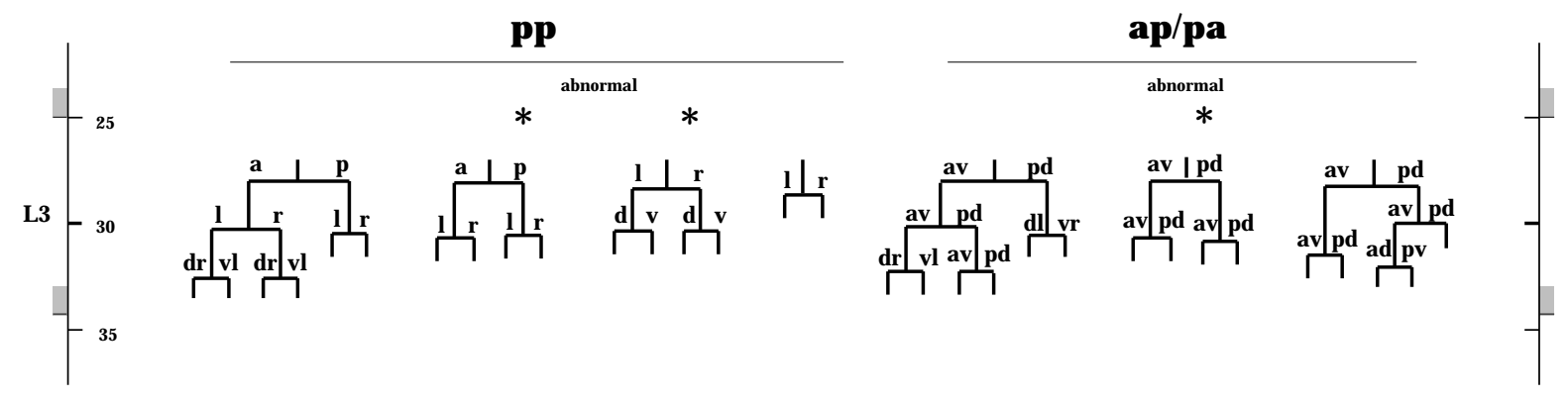

B. Examples of variable abnormal lineages
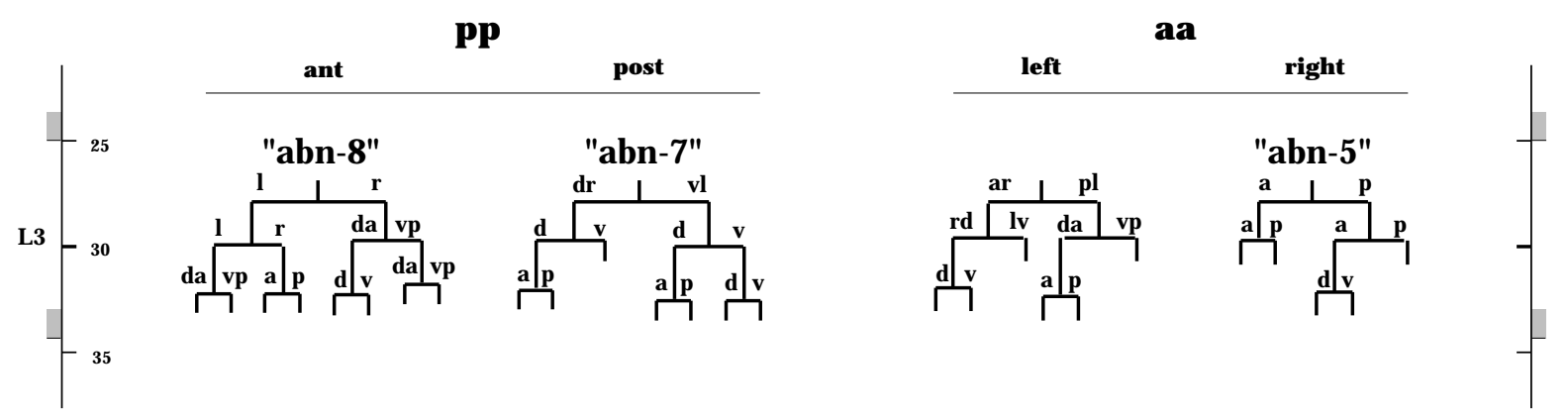

Fig. 5. Abnormal lineages observed in experimental animals. (A) Common abnormal lineages. Three abnormal lineages have been observed frequently and thus have been named $\left(\gamma^{*}, \delta^{*}, \varepsilon^{*}\right) . \gamma^{*}$ and $\delta^{*}$ are both intermediate between $\gamma$ and $\delta$, but differ in the division axes. $\gamma, \delta, \varepsilon$, and $\zeta$ lineages are from Fig. 2. Timing of divisions in abnormal lineages can be variable. The lineage charts for $\gamma^{*}, \delta^{*}, \varepsilon^{*}$ were constructed from abnormal lineages observed in three or more affected animals. (B) Examples of other abnormal lineages. pp lineages from $\mathbf{a a}^{-} \mathbf{a p}^{-} \mathbf{p a}^{-}$animal 275 (Table 1E.1). These lineages are representative of 'abnormal proliferative' lineages. The axes of division vary from animal to animal. aa lineages from $\mathrm{F}^{-} \mathrm{U}^{-} \mathrm{Y} \cdot \mathrm{p}^{-}$animal 203 (Table $1 \mathrm{G}$ ). In this animal, the two aa cells remained left/right. The left aa cell illustrates $\beta_{\tau}$. Although the axes are different, the division pattern is the same as a normal $\beta$ lineage $(3+3$; compare with Fig. 2). We consider $\beta_{\tau}$ lineages to be similar to normal $\beta$ lineages. The right aa cell is an example of an abn-5 lineage. Regardless of division axes, any cell that produces 5 progeny in a $2+3$ pattern is considered abn- 5 . 
observed lineages do not clearly suggest a fate. Consideration of the data in these terms has allowed the extraction of general interpretations from ablations that result in a mixture of abnormal lineages.

Table 1 includes the results from the $150 \mathrm{~B}$ lineages that we have followed in this study. Much of the data from this Table are also summarized in simpler Figures and Tables. We have divided the Results into four sections. First, we characterize interactions of the other male-specific blast cells $(\mathrm{F}, \mathrm{U}, \mathrm{Y})$ on the fate of B.a progeny. This identifies anterior (from $\mathrm{F} / \mathrm{U}$ ) and posterior (from $\mathrm{Y}$ ) positional cues that promote anterior and posterior fates. Second, we characterize the extracellular cues that the other B.a progeny provide for each of the three cell pairs. In general, the other B.a progeny act to promote posterior fate within each pair, providing a distinct posterior positional cue. Third, we investigate the relationship among the identified cues. These experiments allow us to establish modulatory and antagonistic relationships among the cues. We also investigate lateral interactions between cells in each pair, the 'ground state' within each pair, and the possible units of fate specification for each pair. Fourth, we consider what may distinguish the cells in one pair from the cells in another.

I. The male-specific blast cells $(F, U$, and $Y)$ provide positional cues for the three B.a progeny groups

We examined the effect of the other male-specific blast cells on the B progeny because they are close neighbors. The results of these ablations are summarized in Fig. 6. In intact animals, $\mathrm{F}$ and $\mathrm{U}$ lie anterior to $\mathrm{B}$, such that $\mathrm{F}$ is dorsal and $\mathrm{U}$ is ventral to the rectum (see Figs 3, 4). Y lies ventral to $\mathrm{B}$, but the progeny of Y.p are situated more dorsal and pos-

\section{B $\mathbf{F}^{-} \mathbf{U}^{-}$}

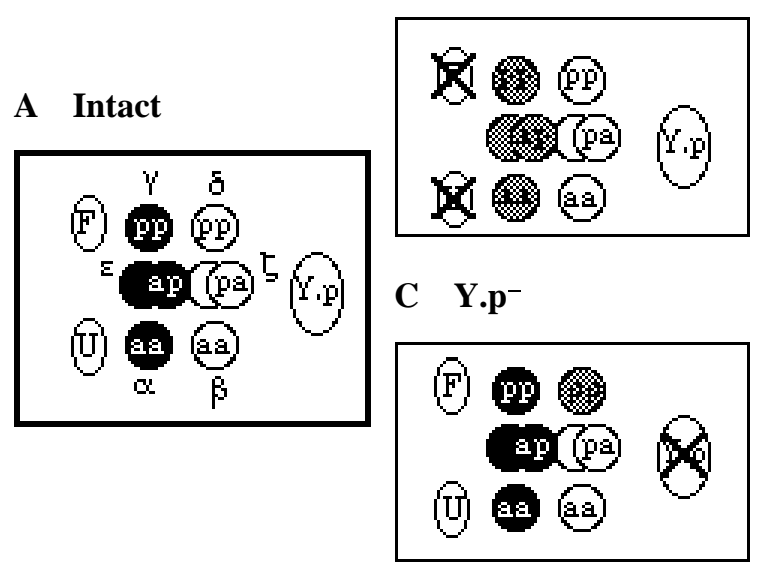

Fig. 6. Illustration of effects of F/U and Y.p ablation on the fates of the eight B.a progeny. F, U, Y.p are drawn to show the approximate position of $F, U$, and Y.p progeny when $B$ is at the 10 cell stage. B.p progeny are not included in this Figure. Anterior is to the left, ventral down. (A) Intact. Black circles indicate anterior fates. White circles indicate posterior fates. (B) Ablation (indicated by $\mathrm{X}$ ) of $\mathrm{F}$ and $\mathrm{U}$ disrupts anterior fates $\gamma, \varepsilon$, and $\alpha$ (shaded circles). In some animals presumptive $\gamma$ (the anterior pp cell) is transformed to $\delta$ and presumptive $\alpha$ is transformed to $\beta$. (C) Ablation of Y.p disrupts posterior fate, $\delta$ (shaded circles). Data of Table 1B,C. terior than the precursor. Thus, F, U, Y.p and their progeny are positioned anterior or posterior, and immediately next to the B cell and its progeny.

\section{A. $\mathrm{F}$ and $\mathrm{U}$ promote anterior fates}

Ablation of $\mathrm{F}$ and $\mathrm{U}$ disrupts the lineages of presumptive $\alpha, \gamma$, and $\varepsilon$, but not $\beta, \delta$ and $\zeta$ (summarized in Fig. 6B; data summary in Table 2; photographs in Fig. 7; data of Table 1B). Presumptive $\alpha$ cells (i.e., the positionally anterior aa cell) produce extra divisions, in many cases with the timing, axes, and number of divisions similar to those seen in a normal $\beta$ lineage. Specifically, presumptive $\alpha$ lineages were abnormal in all seven animals examined, and in $3 / 7$ animals the presumptive $\alpha$ cells produced a complete $\beta$-like lineage. Presumptive $\gamma$ cells, which normally produce six progeny, produce truncated lineages. $3 / 7$ produced four progeny, and $2 / 7$ produced only two. Although the timing and axis of the single division of these cells was slightly irregular, we provisionally interpret these as $\gamma$ to $\delta$ transformations. Finally, 3/7 animals (5/14 sides) had truncated $\varepsilon$ lineages ( $\varepsilon^{*}$, and one abn-5). In these animals the ap cells produced four rather than the usual six progeny.

The strong disruption of anterior fates is only apparent if both $\mathrm{F}$ and $\mathrm{U}$ are ablated (Table 1B.2,3). Ablation of only $\mathrm{F}$ or $\mathrm{U}$ results in essentially normal lineages. One abnormal $\gamma$ lineage was observed in four $\mathrm{F}^{-}$animals, and one abnormal $\alpha$ lineage was observed in four $\mathrm{U}^{-}$animals. In these cases, the fate is disrupted in the anterior cell that is normally closest to the progeny of the ablated cell. Thus, $\mathrm{F}$ and $\mathrm{U}$ are partially redundant in their ability to promote anterior fate. In addition, the lineage disruption is specific to the absence of $\mathrm{F}$ and $\mathrm{U}$, and is not likely the non-specific result of cell damage or nearby debris.

Although $\mathrm{F} / \mathrm{U}$ ablation disrupts anterior fates for all four pairs of cells, the results are variable, and the extent of the defect is not the same for the different pairs. Nevertheless, fates of the anterior cells but not fates of the posterior cells are disrupted in these animals. We conclude that $\mathrm{F}$ and $\mathrm{U}$, or their progeny, are necessary to promote normal anterior fates in each of the four pairs of cells. In the absence of $F$ and $\mathrm{U}$, these cells produce abnormal lineages, and in some cases adopt the fate normally associated with their posterior neighbors.

\section{B. Y.p promotes some posterior fates}

Ablation of Y.p disrupts presumptive $\delta$ lineages (summarized in Fig. 6C; data summary in Table 2; photographs in Fig. 8; data of Table 1C). Presumptive $\delta$ cells divide an extra round, producing up to four progeny. Although the number of progeny increases, and thus might be considered a partial transformation of $\delta$ to $\gamma$ fate, the first division retains the axis and approximate timing associated with the $\delta$ lineage. Therefore, we conclude only that Y.p is required for proper $\delta$ fate. The fate of the presumptive $\beta$ cell was disrupted in $1 / 7$ Y.p ${ }^{-}$animals examined, which may reflect a minor role for Y.p in the aa pair (see Section III.A.1). However, Y.p is not sufficient to specify $\beta$ (see Section II.A). No abnormalities in the lineages of the anterior cells $(\alpha, \gamma$, or $\varepsilon$ ) were observed (7 animals (6 for $\varepsilon)$ ), nor was the $\zeta$ lineage disrupted (12 sides).

The progeny of B.p lie posterior to the four pairs of B.a 
Table 1. Summary of lineages observed in experimental animals

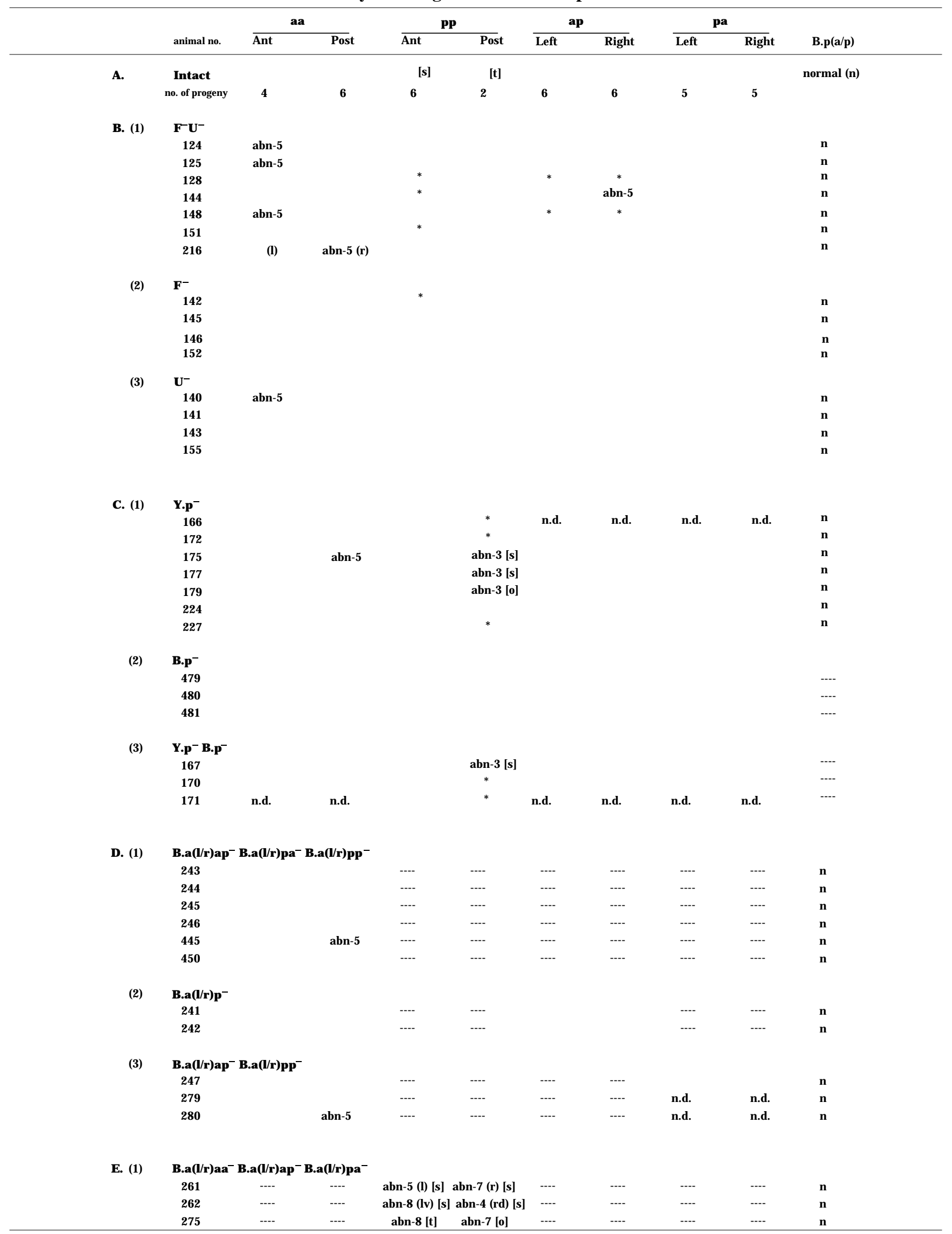


Table 1. Continued

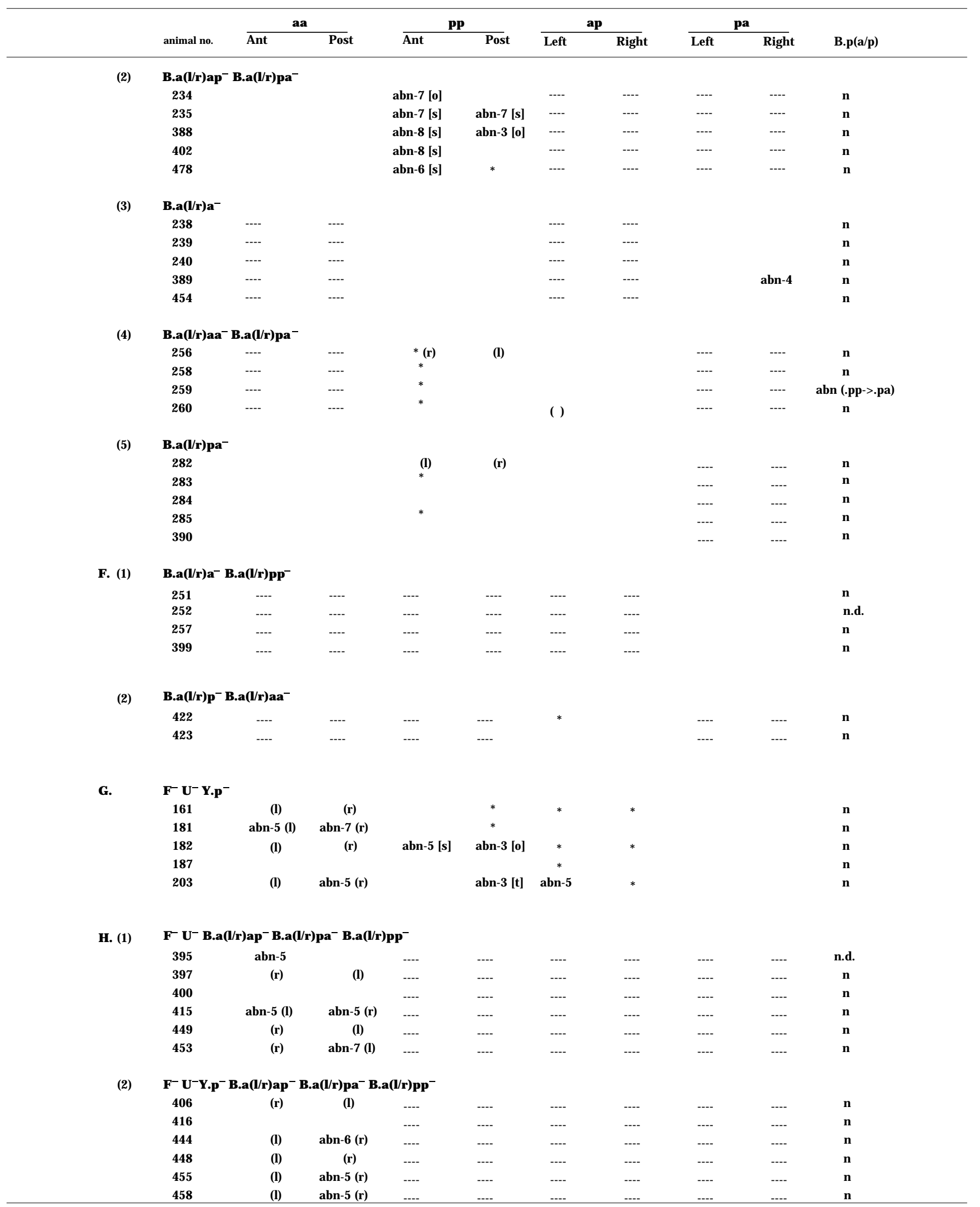


Table 1. Continued

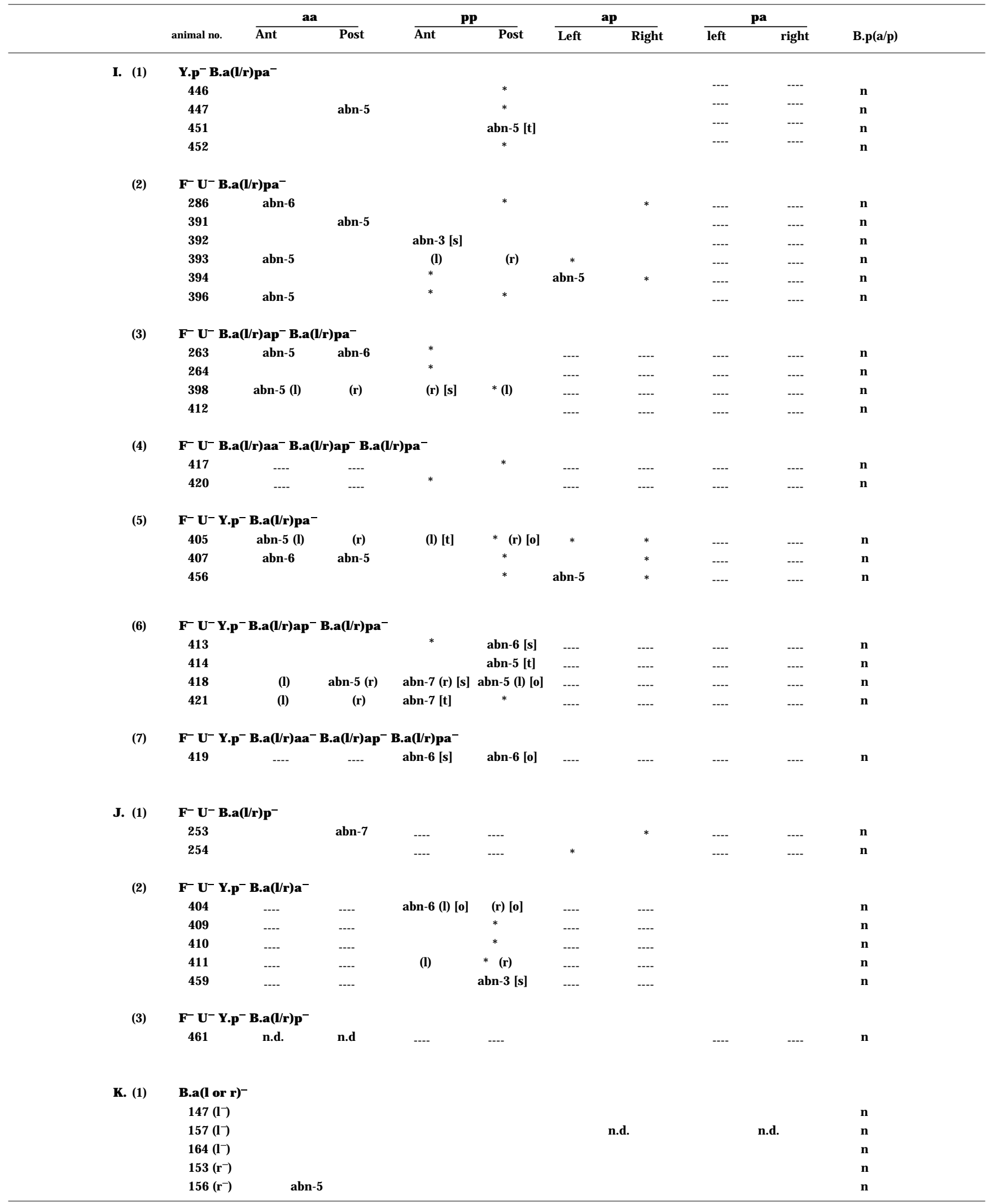


Table 1. Continued

\begin{tabular}{|c|c|c|c|c|c|c|}
\hline & \multirow[b]{2}{*}{ animal no. } & aa & pp & ap & pa & \multirow[b]{2}{*}{ B.p(a/p) } \\
\hline & & Post & $\overline{\text { Ant }}$ & Right & Right & \\
\hline \multirow[t]{8}{*}{$(2)$} & \multicolumn{6}{|c|}{$\mathbf{F}^{-} \mathbf{U}^{-} \mathbf{B} \cdot \mathrm{a}(\mathbf{I} \text { or } \mathbf{r})^{-}$} \\
\hline & $168\left(I^{-}\right)$ & $\beta_{\tau}$ & $\delta$ & $\varepsilon^{*}$ & abn-4 & $\mathrm{n}$ \\
\hline & $180\left(I^{-}\right)$ & $\beta_{\tau}$ & $\delta^{*}$ & $\varepsilon$ & $\zeta_{\tau}$ & $\mathrm{n}$ \\
\hline & $159\left(r^{-}\right)$ & abn-6 & $\gamma^{*}$ & $\varepsilon^{*}$ & $\zeta$ & $\mathrm{n}$ \\
\hline & $160\left(r^{-}\right)$ & $\beta_{\tau}$ & $\delta$ & $\varepsilon$ & $\zeta$ & $\mathrm{n}$ \\
\hline & $162\left(r^{-}\right)$ & $\beta_{\tau}$ & $\delta$ & $\varepsilon$ & $\zeta$ & $\mathrm{n}$ \\
\hline & $165\left(r^{-}\right)$ & $\beta_{\tau}$ & $\delta$ & abn-5 & $\zeta$ & $\mathrm{n}$ \\
\hline & $169\left(r^{-}\right)$ & $\beta$ & $\delta$ & $\varepsilon$ & $\zeta$ & $\mathrm{n}$ \\
\hline \multirow[t]{5}{*}{ (3) } & \multicolumn{6}{|c|}{$\mathbf{F}^{-} \mathbf{U}^{-}$Y.p- B.a(I or r) $)^{-}$} \\
\hline & $174\left(I^{-}\right)$ & $\beta_{\tau}$ & $\gamma^{*}$ & $\varepsilon$ & $\zeta$ & $\mathrm{n}$ \\
\hline & $213\left(I^{-}\right)$ & $\beta_{\tau}$ & abn-3 [s] & $\varepsilon$ & $\zeta$ & $\mathrm{n}$ \\
\hline & $173\left(r^{-}\right)$ & $\alpha_{\tau}$ & $\gamma^{*}$ & $\varepsilon$ & $\zeta$ & $\mathrm{n}$ \\
\hline & $176\left(r^{-}\right)$ & $\beta_{\tau}$ & $\delta^{*}$ & $\varepsilon$ & $\zeta$ & $\mathrm{n}$ \\
\hline
\end{tabular}

L. (1) $\quad \mathbf{F}^{-} \mathbf{U}^{-} \mathbf{Y}^{-} \mathbf{p}^{-}$B.a(I/r)p $\mathbf{p}^{-}$B.a(I or $\left.\mathbf{r}\right) \mathbf{a}^{-}$B.a(I or $\left.\mathbf{r}\right) \mathrm{ap}^{-}$

\begin{tabular}{|c|c|c|c|c|c|c|c|c|}
\hline $457\left(I^{-}\right)$ & $\alpha_{\tau}$ & --- & --- & ---- & ---- & ---- & ---- & abn (damagec \\
\hline $460\left(I^{-}\right)$ & $\alpha_{\tau}$ & --- & --- & --- & ---- & ---- & --- & $\mathrm{n}$ \\
\hline $463\left(I^{-}\right)$ & $\beta_{\tau}$ & --- & --- & --- & --- & --- & --- & $n$ \\
\hline $464\left(r^{-}\right)$ & $\alpha_{\tau}$ & --- & ---- & ---- & ---- & ---- & ---- & $n$ \\
\hline $465\left(r^{-}\right)$ & $\alpha_{\tau}$ & ---- & ---- & ---- & --- & ---- & ---- & $n$ \\
\hline
\end{tabular}

(2) $\quad \mathbf{F}^{-} \mathbf{U}^{-}$Y.p- B.a(I/r)a- B.a(I or r)p- $\mathbf{p}^{-}$B.a(I or $\left.\mathbf{r}\right) \mathbf{p a}^{-}$

\begin{tabular}{|c|c|c|c|c|c|c|c|c|}
\hline $466\left(I^{-}\right)$ & ---- & ---- & abn-5 [s] & - & - & --- & ---- & $n$ \\
\hline $467\left(I^{-}\right)$ & --- & --- & $\gamma_{\tau[s]}$ & ---- & ---- & --- & --- & $\mathrm{n}$ \\
\hline $468\left(I^{-}\right)$ & --- & --- & abn-6 [s] & --- & --- & --- & --- & $\mathrm{n}$ \\
\hline $469\left(r^{-}\right)$ & --- & --- & $\gamma_{\tau}[\mathrm{s}]$ & --- & --- & --- & --- & $\mathrm{n}$ \\
\hline $462\left(r^{-}\right)$ & ---- & ---- & abn-8 [s] & ---- & --- & --- & --- & abn (damaged) \\
\hline
\end{tabular}

(3) $\quad \mathbf{F}^{-} \mathbf{U}^{-}$Y.p. $\mathbf{p} \cdot \mathbf{a}(\mathbf{I} / \mathbf{r}) \mathbf{a}^{-}$B.a(l/r)pp-

$\begin{array}{llllllllll}470 & --- & --- & --- & --- & \zeta & \zeta & n \\ 471 & --- & --- & --- & --- & --- & --- & \zeta & \zeta & n \\ 472 & --- & --- & --- & --- & --- & --- & \zeta & \zeta & n \\ 473 & --- & --- & --- & --- & --- & -- & \zeta & \zeta_{\tau} & n\end{array}$

(4) $\mathbf{F}^{-} \mathbf{U}^{-}$Y.p- B.a(I/r)p $\mathbf{p}^{-}$B.a(I/r)aa-

\begin{tabular}{|c|c|c|c|c|c|c|c|c|}
\hline 474 & --- & --- & ---- & --- & $\varepsilon_{\tau}$ & $\varepsilon_{\tau}$ & ---- & ---- \\
\hline 475 & --- & --- & --- & --- & $\varepsilon_{\tau}$ & abn-7 & ---- & ---- \\
\hline 476 & ---- & --- & --- & ---- & $\varepsilon_{\tau}$ & $a b n-\varepsilon$ & ---- & ---- \\
\hline 177 & -..- & -.-- & -.-- & $\ldots$ & $\varepsilon_{\tau}$ & $\varepsilon_{\tau}$ & .... & $\ldots$ \\
\hline
\end{tabular}

Each line represents the observed lineages for one animal. Each animal is identified by a unique number. A dash indicates that the cell was ablated in that animal. $\mathrm{n}$ indicates normal B.p lineage. n.d. indicates that the cell was present, but not followed to completion of the lineage. abn- $n$ indicates that the lineage was abnormal, but produced $n$ progeny. If the cells of a pair failed to migrate, the side is indicated in parentheses (e.g., left is (l), left ventral is (lv)). Canonical $\gamma^{*}, \delta^{*}$, and $\varepsilon^{*}$ lineages, and examples of some other abnormal lineages, are illustrated in Fig. 5. The number of progeny produced by each cell in the inact animal is listed in Section A for reference. For ablations in Sections $\mathrm{K}$ and $\mathrm{L}$ we have grouped bilaterally symmetrical experiments together, and indicate the actual cell ablated in parentheses after the number of the animal (e.g., in K.1 $147\left(1^{-}\right)$is B.al' ${ }^{-}$).

Cell lineages are characterized by the number, axes, and timing of divisions. Of these, number of divisions is the most objective criterion. Our analyses suggest that although first division axis may reflect cell state in the pp pair, it appears not to be predictive in the aa pair (it was never fundamentally disrupted in the ap/pa pairs). Thus, we have utilized the symbol $\tau$ (as in $\beta_{\tau}$ ), which indicates that the cell division pattern was topologically that lineage, although the division axes were skewed. For instance, if an aa cell fails to migrate, it will often divide along an anterior/posterior axis. However, if both anterior and posterior cells produce three progeny, the lineage is $\beta_{\tau}$ because of the $3+3$ pattern of progeny, regardless of the division axis (illustrated in Fig. 5). Similarly, $\gamma_{\tau}$ indicates a $4+2$ pattern of progeny, but abnormal division axes. Note that all lineages within a class of lineages (e.g., abn-5) are topologically the same ( 2 progeny from one daughter, 3 from the other, or $2+3$; see Fig. 5$)$. Specifically, abn-3 are (1+2), abn- $4(2+2)$, abn-5 (2+3), abn- 6 $(3+3$ in a pp lineage, $2+4$ in an aa lineage), abn-7 (3+4), abn-8 (4+4). In general, abnormal lineages from cells that migrate properly retain the axes associated with the normal lineage (l-r, or transverse [t] for presumptive $\alpha, \beta$, and $\delta$, a-p or sagittal [s] for presumptive $\gamma$, av-pd for presumptive $\varepsilon$ and $\zeta$ ). If aa cells fail to migrate, the initial axis is generally a-p. If many B.a neighbors are absent, an ap or pa axis is often a-p. Although it is not fully predictive, the first axis of division differs in $\gamma$ lineages compared with $\delta$ lineages, and it may reflect cell state in the pp pair. Because the cell lineage can be variable, this axis is indicated for the abnormal pp cell lineages in brackets. [s] sagittal, [t], transverse, [o], oblique. $\gamma$ and $\gamma^{*}$ lineages are [s], $\delta$ and $\delta^{*}$ lineages are [t]. Not every division of the left ap lineage was observed in G.4, animal 260. 

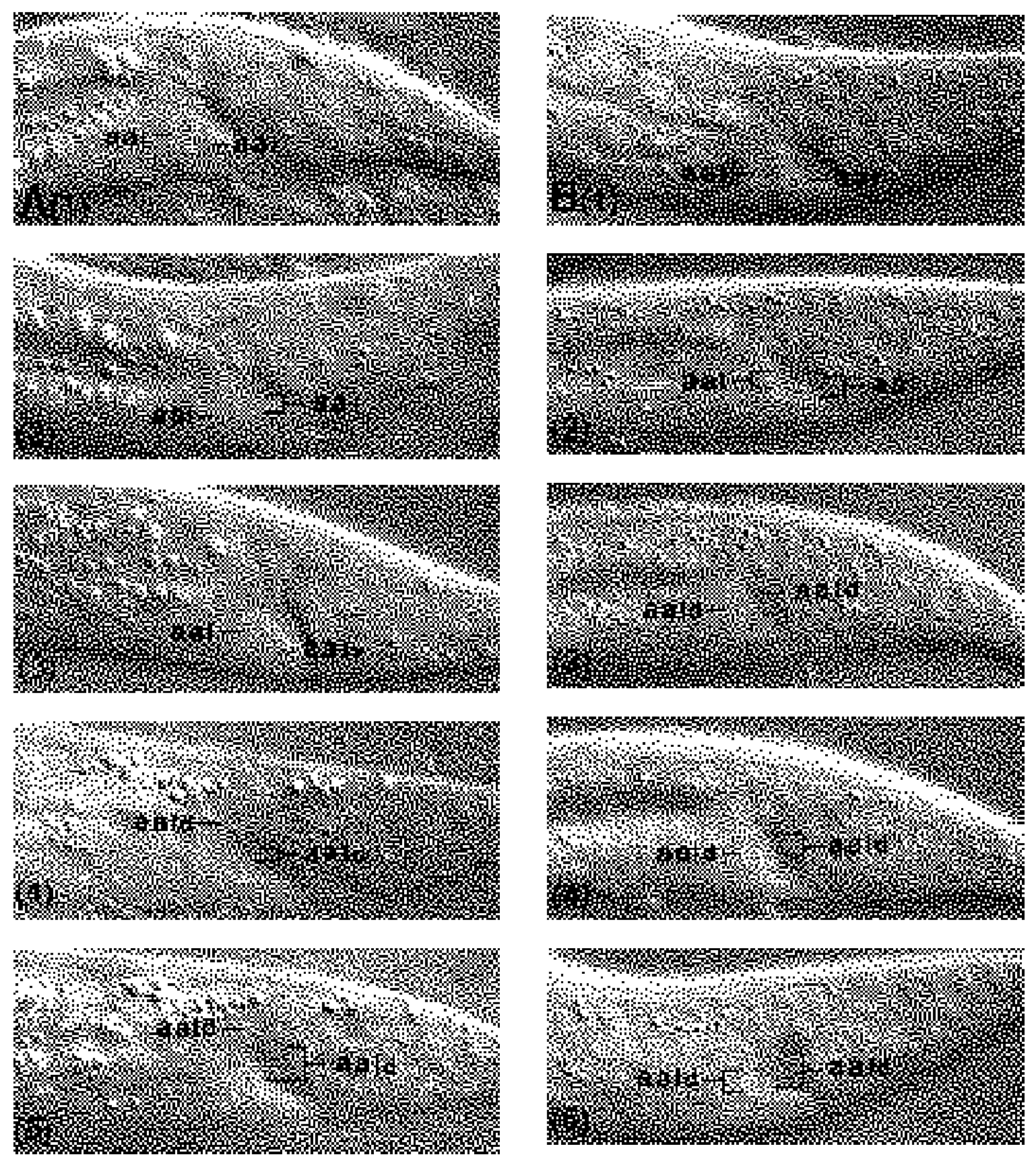

Fig. 7. The transformation of $\alpha$ to $\beta$ fate observed in $\mathrm{F}^{-} \mathrm{U}^{-}$animals. Nomarski photomicrographs, left lateral view. (A) Intact. (B) $\mathrm{F}^{-} \mathrm{U}^{-}$. (A.1-3) In intact animals, the daughters of presumptive $\beta$ divide prior to the daughters of presumptive $\alpha$ (average difference 40 minutes). (A.1) Both presumptive $\alpha .1$ (anterior aal) and $\beta .1$ (posterior aal) are visible. (A.2) Presumptive $\beta .1$ divides (metaphase). (A.3) Nuclei of presumptive $\beta .1$ daughters reform. Presumptive $\beta . l v$ is visible in the same plane of focus as the yet undivided presumptive $\alpha .1$. (B.1-3) Disrupted fates in $\mathrm{F}^{-} \mathrm{U}^{-}$animals

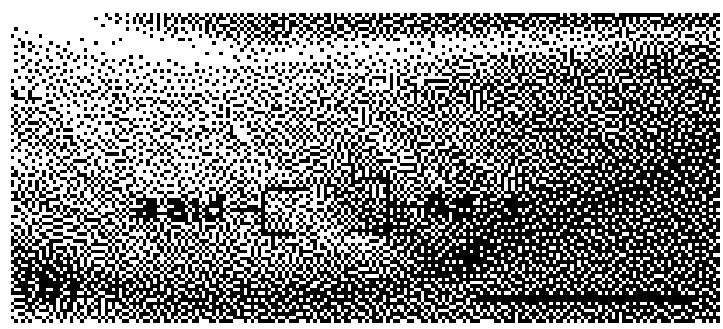
are apparent in the division of the aa cell daughters. (B.1) Nuclei of anterior and posterior aal cells (presumptive $\alpha .1$ and $\beta .1$, respectively) are apparent. (B.2) Both cells begin to divide. (B.3) Nuclei of daughters of both presumptive $\alpha .1$ and $\beta .1$ reform. Presumptive $\alpha .1 \mathrm{~d}$ and $\beta$.ld are indicated. (A.4,5) In intact animals, $\beta$.(1/r)d divide. (A.4) Metaphase of presumptive $\beta .1 d$. The nucleus presumptive $\alpha .1 \mathrm{l}$ is also labeled. (A.5) The daughter nuclei of presumptive $\beta .1 \mathrm{~d}$ reform. Presumptive $\alpha .1 d$ remains intact. (B.4-6) Both presumptive $\alpha .(1 / \mathrm{r}) \mathrm{d}$ and $\beta$.(1/r)d divide in transformed $\mathrm{F}^{-} \mathrm{U}^{-}$animals. (B.4) Presumptive $\beta .1 d$ metaphase. (B.5) Presumptive $\alpha$.ld anaphase. Daughter nuclei of presumptive $\beta$.ld are reforming. (B.6) Daughter nuclei of both presumptive $\alpha .1 \mathrm{~d}$ and $\beta$.ld are visible in this plane of focus. Scale bar, $20 \mu \mathrm{m}$. 
Table 2. Summary of lineage disruptions that result from F/U and Y.p ablation

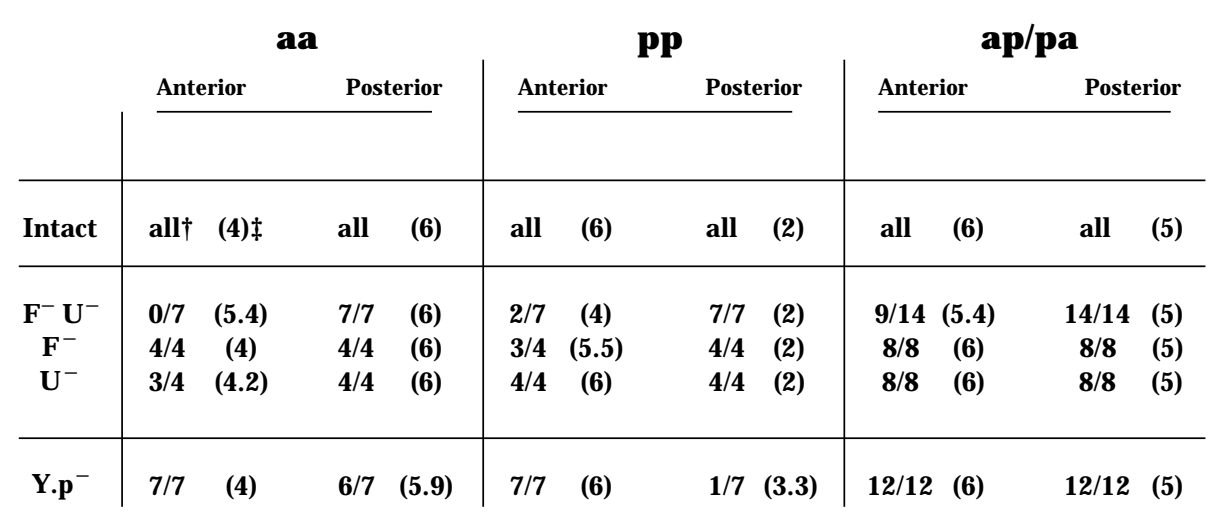

Data from Table 1B,C. Ablation of F and $\mathrm{U}$ together disrupts anterior $(\alpha, \gamma, \varepsilon)$ fates, but removal of only $\mathrm{F}$ or $\mathrm{U}$ generally results in normal lineages. Ablation of Y.p disrupts posterior $(\delta$ and rarely $\beta$ ) fates. $†$ Normal lineages/lineages followed; łaverage number of progeny in parentheses.

progeny, and thus might also promote posterior fates. However, ablation of B.p does not disrupt the fates of B.a progeny. In addition, ablation of B.p and Y.p does not appreciably enhance the effect of ablation of Y.p alone (Table 1C.2,3). We conclude that Y.p or its progeny is necessary to promote normal posterior fate in the pp pair.

\section{Summary of male-specific blast cell effects}

We have demonstrated that the male-specific blast cells $\mathrm{F}$, $\mathrm{U}$, and Y (or their progeny) provide at least some of the positional cues that specify anterior versus posterior fates in the aa, pp, and ap/pa pairs. The disruptions and fate transformations resulting from ablation are variable, and not complete. We cannot distinguish whether this is a result of the limitations of cell ablation techniques in general, whether it is a result of the methods we have used, whether it reflects an inherent variability of the system, or whether other cells provide additional positional cues. Nevertheless, we have found that distinct cell fates are disrupted, and in some cases complete transformation of fate is observed.

\section{Activity of B.a(l/r)xx cells on the cell pairs}

At the 10 cell stage, many of the neighbors of the cells of each pair are other B.a progeny. We have investigated the interactions that occur among the B.a progeny. For sim-
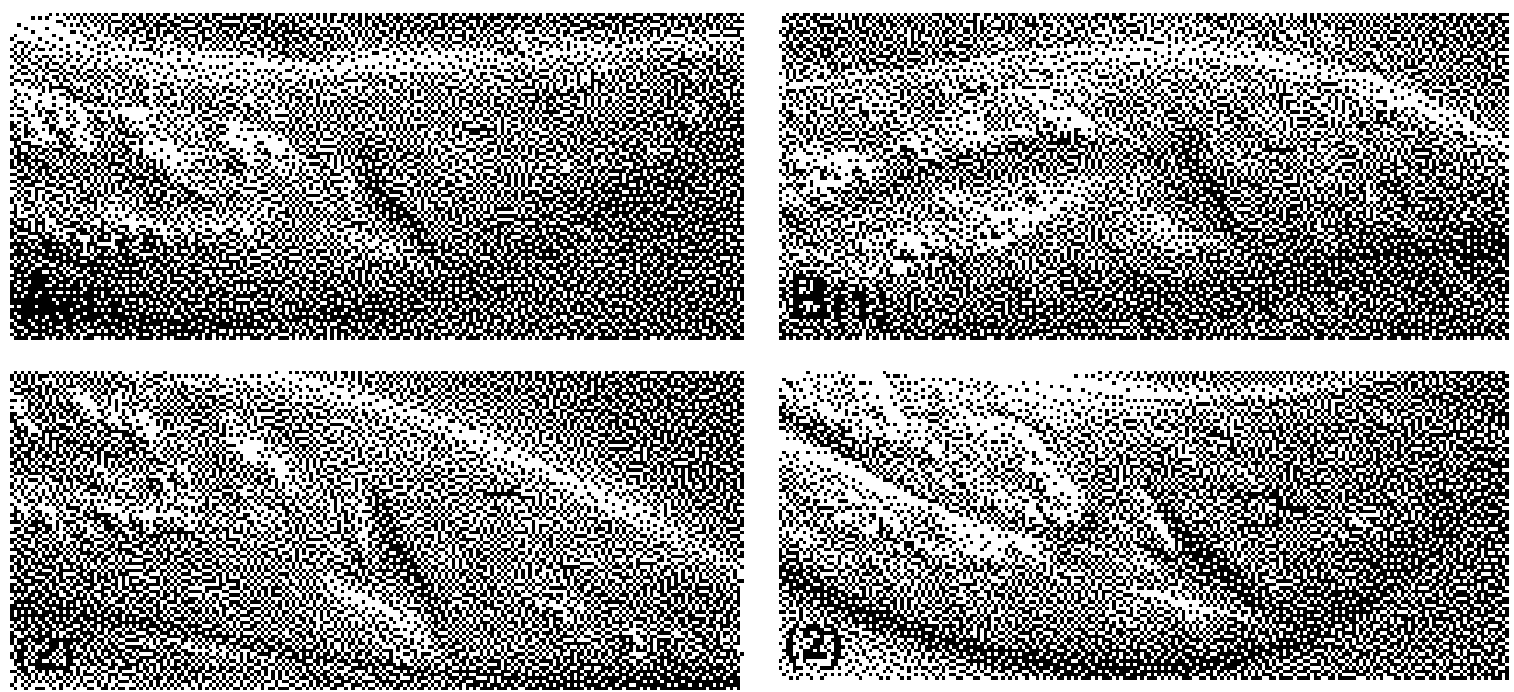

Fig. 8. Extra divisions in the presumptive $\delta$ lineage observed in Y.p $\mathrm{p}^{-}$males. Nomarski photomicrographs, left lateral view. (A) Intact. (B) Y.p ${ }^{-}$. (A) In intact animals, presumptive $\delta$ divides only once. (A.1) $\delta .1$ is indicated by a line. (A.2) At a later timepoint (after neighboring cells have divided), $\delta .1$ remains intact. (B) In Y.p $\mathrm{p}^{-}$animals, presumptive $\delta$.(1/r) often divide. (B.1) Presumptive $\delta .1$ is visible. (B.2) Presumptive $\delta .1$ metaphase. (B.3) Nuclei of presumptive $\delta .1$ daughter cells reform. Presumptive $\delta . l$ is visible in this plane of focus. Scale bar, $20 \mu \mathrm{m}$.

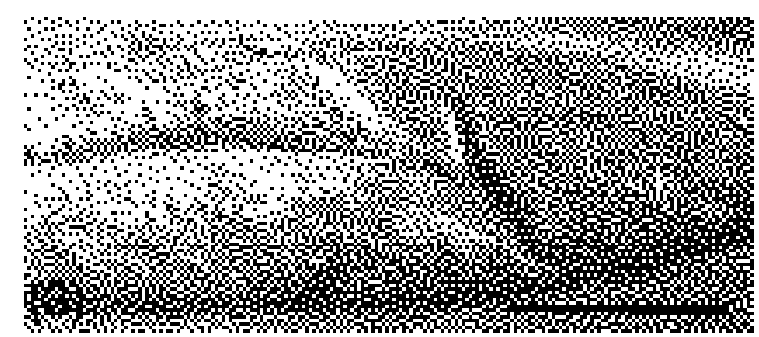


A Intact

(1)

(2)

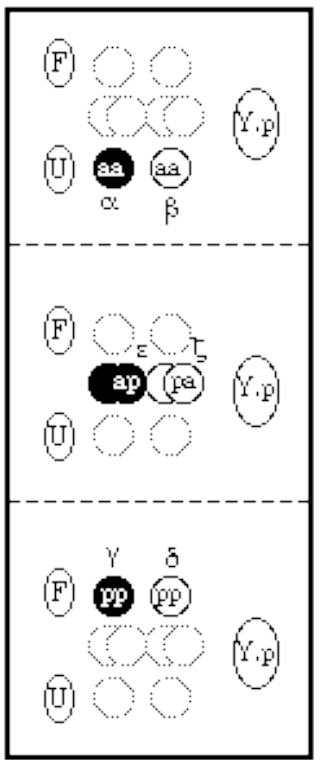

B

(1)

(2)

(3)

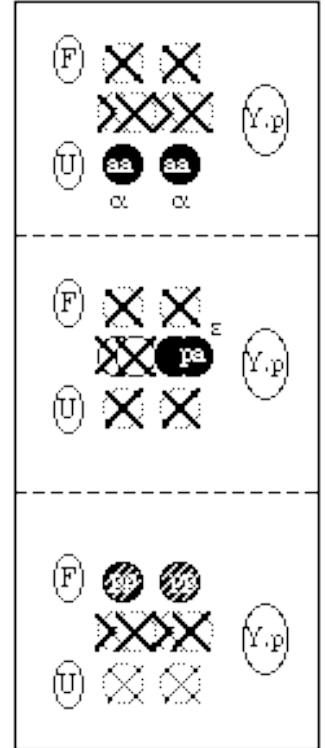

Fig. 9. Schematic comparison of the effects of removal of the other B.a progeny on each of the three cell pairs. In general, the posterior cell of the pair adopts a more anterior-like fate (anterior left, ventral down). (A) Intact. Black circles represent anterior fates, white circles represent posterior fates. (B) Experimental. (B.1) Posterior aa cells adopt $\alpha$ (anterior) fate in $\mathbf{a p}^{-} \mathbf{p a}^{-} \mathbf{p} \mathbf{p}^{-}$ animals. (B.2) pa cells adopt $\varepsilon$ (anterior) fate in $\mathbf{a a}^{-} \mathbf{a p}^{-} \mathbf{p} \mathbf{p}^{-}$ animals. (B.3) Both anterior and posterior pp cells produce abnormal proliferative lineages (indicated by shading; example in Fig. 5B) in $\mathbf{~ a p}^{-} \mathbf{p a}^{-} \mathbf{a a}^{-}$animals. The effect is also seen if only ap and pa are ablated. Data of Table 1D,E,F.

plicity, we present the data for each cell pair separately. These results are summarized in Fig. 9.

\section{A. Ventral group (aa cells)}

To characterize any influences on the aa pair from the other six B.a progeny, we first isolated the pair by ablation of ap, pa, and pp (Table 3; data of Table 1D,E.2). If anterior cues from $\mathrm{F} / \mathrm{U}$ and possible posterior cues from Y.p are sufficient to promote normal $\alpha$ and $\beta$ fates in the aa pair,

Table 3. Summary of lineage disruptions in the aa cell pair that result from ablation of other B.a progeny

\begin{tabular}{|c|c|c|c|c|}
\hline & \multicolumn{3}{|c|}{ aa } & \\
\hline & \multicolumn{2}{|c|}{ Anterior } & \multicolumn{2}{|c|}{ Posterior } \\
\hline & \multicolumn{2}{|c|}{$\alpha$} & \multicolumn{2}{|c|}{$\beta$} \\
\hline Intact & allt & $(4) \ddagger$ & all & (6) \\
\hline$a p^{-} p a^{-} p p^{-}$ & $6 / 6$ & (4) & $1 / 6$ & (4.5) \\
\hline$p^{-} \mathbf{p p}^{-}$ & $2 / 2$ & (4) & $2 / 2$ & (6) \\
\hline$a p^{-} \quad p^{-}$ & $3 / 3$ & (4) & $2 / 3$ & (5.7) \\
\hline $\operatorname{ap}^{-} p a^{-}$ & $4 / 4$ & (4) & $4 / 4$ & (6) \\
\hline
\end{tabular}

Data from Table 1D,E.2. Removal of ap/pa/pp cells results in the disruption of posterior $(\beta)$ fate. In general, presumptive $\beta$ cells adopt an $\alpha$ fate. However, if any other pair of cells remain $\left(\mathbf{a p}^{-} \mathbf{p a}^{-}, \mathbf{a p}^{-} \mathbf{p} \mathbf{p}^{-}\right.$, or $\mathbf{p a}^{-}$ $\left.\mathbf{p p}^{-}\left[\mathrm{B} \cdot \mathrm{a}(1 / \mathrm{r}) \mathrm{a}^{-}\right]\right)$, the presumptive $\beta$ will be essentially normal. $\dagger$ normal lineages/lineages followed; faverage number of progeny in parentheses.

Table 4. Summary of lineage disruptions in the ap/pa pairs that result from ablation of other B.a progeny

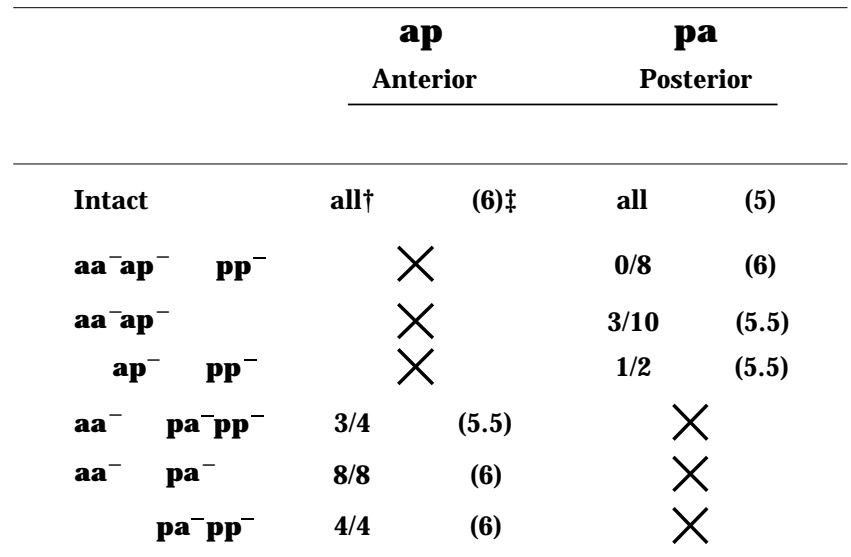

Data from Table 1D,E,F. Each animal has two ap/pa pairs, which are considered independently for this Table (i.e., $10 \mathbf{a a}^{-} \mathbf{a p}^{-}$represents 5 animals). Removal of aa/ap/pp cells results in the disruption of pa fate. The pa cells generate $\varepsilon$ lineages. If other pairs remain (aa-ap- [B.a(l/r)a-], or ap-pp-), the pa cells will sometimes generate a $\zeta$ lineage, and sometimes an $\varepsilon$ lineage. Removal of $\mathbf{a a} / \mathbf{p a} / \mathbf{p p}$ (or a subset thereof) generally does not disrupt the fate of ap cells. X indicates that the cell is absent. †normal lineages/lineages followed; łaverage number of progeny in parentheses.

then aa cells isolated from the other B.a progeny should produce normal lineages. However, we find that the other B.a progeny are necessary for proper specification of fate. Specifically, ablation of all of the other B.a progeny results in truncation of the lineage of the presumptive $\beta$ cell ( 5 of 6 animals). Since the axes and timing, as well as number of progeny of these cells resembles those associated with a normal $\alpha$ lineage, we consider this to be a $\beta$ to $\alpha$ transformation. Thus the B.a progeny promote posterior $(\beta)$ fate in the aa pair. The presence of any pair is sufficient to promote normal $\beta$ lineages. Ablation of ap and pa, or ap and pp, or pa and pp $\left(\mathrm{B} . \mathrm{a}(\mathrm{l} / \mathrm{r}) \mathrm{p}^{-}\right)$generally results in normal lineages from the presumptive $\alpha$ and $\beta$ cells. Thus the cell pairs are redundant in their ability to promote $\beta$ fate.

\section{B. Lateral groups (ap/pa cells)}

The other B.a progeny act to promote posterior $\zeta$ fate in the pa cells (Fig. 10; Table 4; data of Table 1D.3,E.3,F). Ablation of the other six B.a progeny causes pa cells to produce $\varepsilon$ lineages. If one other pair of B.a progeny remain, the pa cells will sometimes produce an $\varepsilon$ lineage, and other times a $\zeta$ lineage $\left(\mathbf{a a}^{-}\right.$and $\mathbf{a p}^{-}\left(\mathrm{B} . \mathrm{a}(\mathrm{l} / \mathrm{r}) \mathrm{a}^{-}\right)$; $\mathbf{a p}^{-}$and $\mathbf{p p}^{-}$ lineages; $\mathbf{a a}^{-} \mathbf{p p}^{-}$by examination of anatomy only (data not shown)). We conclude that the other B.a progeny act to promote posterior fate in the pa cells. Consistent with this result, the $\varepsilon$ fate of ap does not depend on the presence of other B.a progeny.

\section{Dorsal group (pp cells)}

Ablation of all other B.a progeny (aa, ap, and pa) results in abnormal lineages produced by both the presumptive $\gamma$ and the presumptive $\delta$ cells (Table 5; data of Table 1E). These abnormal lineages are novel in that they can result in up to eight progeny, which is more than is produced by 

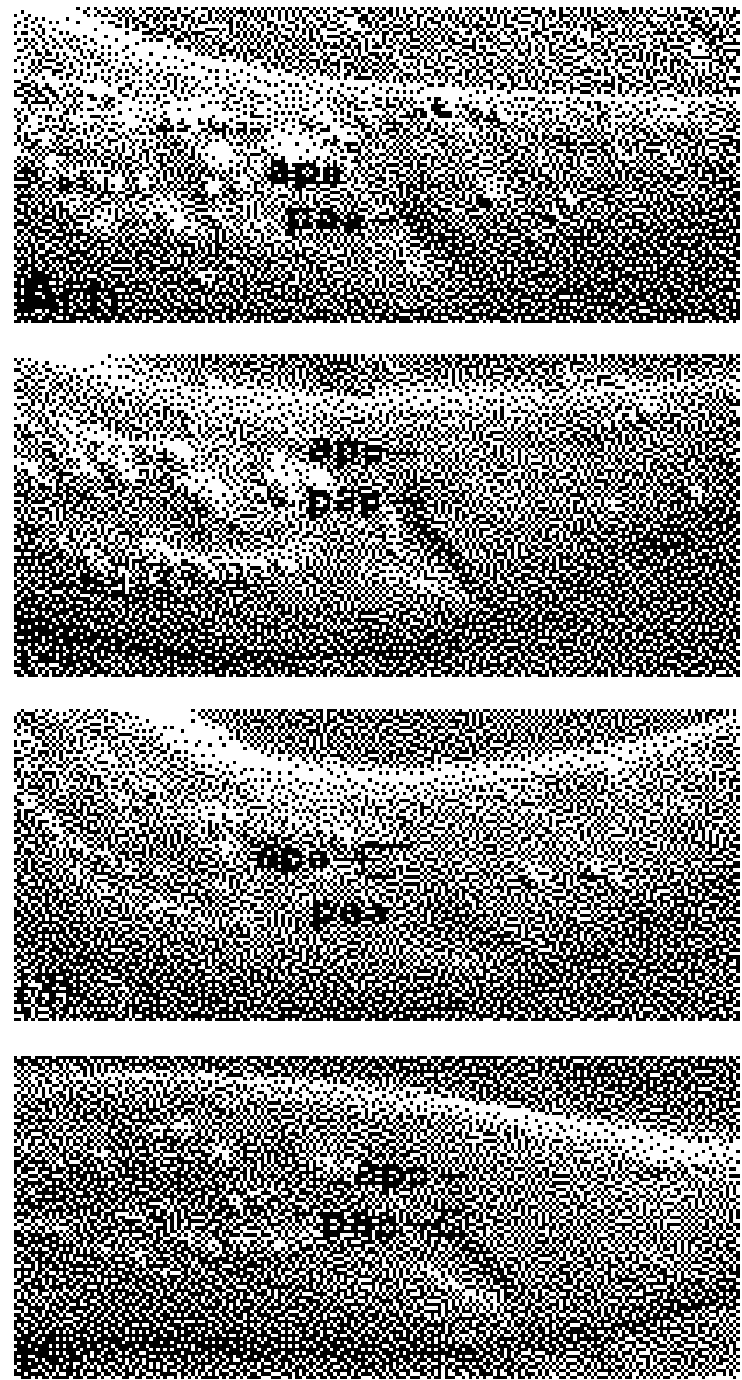
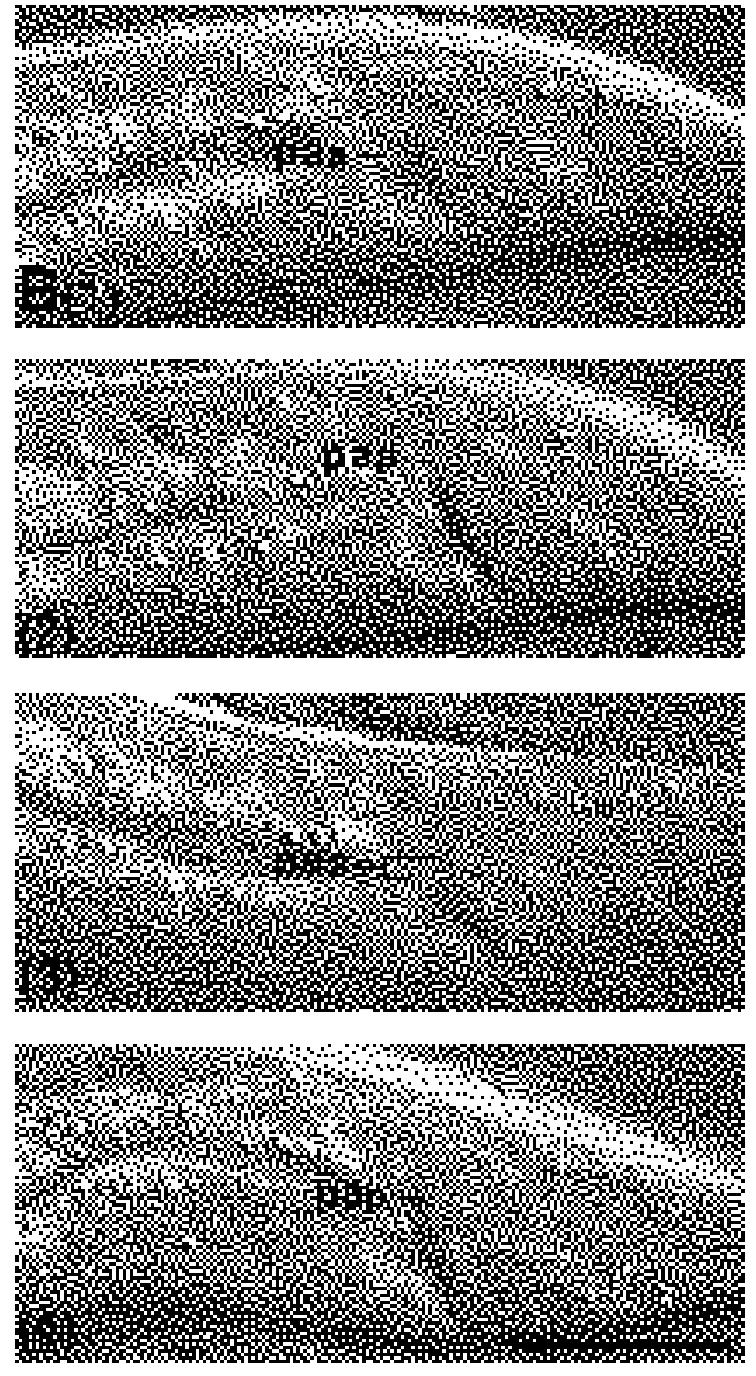

Fig. 10. The transformation of pa to $\varepsilon$ fate in the absence of other B.a progeny. As with aa fates (Fig. 7), differences between $\varepsilon$ and $\zeta$ lineages are apparent in the timing of division of the progeny of ap and pa. The anteroventral daughter of $\varepsilon$ divides prior to the posteriodorsal daughter. In intact animals (A), ap produce $\varepsilon$ lineages, and pa produce $\zeta$ lineages. In an $\varepsilon$ lineage, the apa (A.1) cell is larger than app (A.2), and divides first (A.3,4). In a $\zeta$ lineage, the pap (A.2) cell is larger than paa (A.1), and divides first (A3,4). (B) In the absence of other B.a progeny, pa will adopt $\varepsilon$ fate. This transformation sometimes occurs if a subset of other B.a progeny are absent, as shown in this B.a(1/r) $\mathrm{a}^{-}\left(\mathbf{a a}^{-} \mathbf{a p}^{-}\right)$animal (see Table 1E.3). In this animal, paa (B.1) is larger than pap (B.2), and divides first (B.3,4). Both daughters of paa divide, consistent with an $\varepsilon$ lineage (not shown). Nomarski photographs are of left lateral $($ A.1,3; B.1,3) and left medial (A.2,4; B.2,4) focal planes. Scale bar, $20 \mu \mathrm{m}$.

either normal $\gamma$ or $\delta$ lineages (example in Fig. 5). For simplicity they can be thought of as $\gamma$ lineages with $\gamma$.p behaving like $\gamma$.a (see below). These abnormal lineages are also observed when only ap and pa are ablated. The results of experiments that ablate B.a progeny in different combinations indicate that either ap or pa is sufficient to prevent the abnormal proliferative lineages, and thus the pairs are redundant. We propose that the ap and pa cells play two roles in $\gamma / \delta$ fate specification. One role is to promote proper execution of the $\gamma$ lineage. This function ensures that a specified $\gamma$ has six progeny, in a $4+2$ pattern ( 4 progeny from one daughter, 2 from the other, see Table 1 legend). The other role is to promote posterior $(\delta)$ fate. Thus in the absence of ap/pa/(aa), presumptive $\delta$ adopts a more anterior-like fate. However, because of the second function of the ap/pa/(aa) cells, neither presumptive $\gamma$ nor presumptive $\delta$ properly executes the $\gamma$ lineage. We present further evidence for this two step fate specification model in Section III.C.

Removal of ap and aa (by ablation of the precursors B.a(l/r)a) results in normal $\gamma$ and $\delta$ lineages. In some of these animals the pa cells produce $\varepsilon$ lineages (see above; Table 1E.3). Thus, the pa cells are sufficient to promote normal $\gamma$ and $\delta$ lineages, and this function is independent of their own fate. Removal of aa and pa (or pa alone) results in truncation of presumptive $\gamma$ lineages, similar to the lineages in an $\mathrm{F}^{-} \mathrm{U}^{-}$animal. Thus, the pa cells appear to play a role in two distinct processes. Together with the ap cells, the pa cells act to inhibit extra proliferation in both presumptive $\gamma$ and $\delta$. Alone, they function to increase 
Table 5. Summary of lineage disruptions in the pp cell pair that result from ablation of other B.a progeny

\begin{tabular}{|c|c|c|c|c|}
\hline & \multicolumn{4}{|c|}{ pp } \\
\hline & \multicolumn{2}{|c|}{ Anterior } & \multicolumn{2}{|c|}{ Posterior } \\
\hline & \multicolumn{2}{|c|}{$\gamma$} & \multicolumn{2}{|c|}{$\delta$} \\
\hline Intact & allt & (6)‡ & all & (2) \\
\hline $\mathrm{aa}^{-} \mathbf{a p}{ }^{-} \mathrm{pa}^{-}$ & $0 / 3$ & (7) & $0 / 3$ & (6) \\
\hline appa $^{-}$ & $0 / 5$ & (7.2) & $2 / 5$ & (3.6) \\
\hline$a^{-} a p^{-}$ & $5 / 5$ & (6) & $5 / 5$ & (2) \\
\hline $\mathbf{a a}^{-} \quad \mathbf{p a}^{-}$ & $0 / 4$ & (4) & $4 / 4$ & (2) \\
\hline $\mathbf{p a}^{-}$ & $1 / 5$ & (3.6) & $5 / 5$ & (2) \\
\hline
\end{tabular}

Data from Table 1E. Removal of aa/ap/pa cells results in the disruption of anterior $(\gamma)$ and posterior $(\delta)$ fate. Both cells generally undergo abnormal proliferative lineages, producing up to 8 progeny (example in Fig. 5B). A similar effect is seen if only ap/pa cells are ablated. Removal of aa/ap cells $\left(\mathrm{B} . \mathrm{a}(\mathrm{l} / \mathrm{r}) \mathrm{a}^{-}\right)$results in essentially normal lineages. However, removal of pa (alone or with aa) disrupts presumptive $\gamma$ fate. In these animals, presumptive $\gamma$ undergoes truncated lineages similar to those seen in $\mathrm{F}^{-} \mathrm{U}^{-}$animals. †normal lineages/lineages followed; †average number of progeny in parentheses.

proliferation of presumptive $\gamma$. Although they promote $\gamma$ fate in both (or $\gamma$ and $\delta$ fate), the effects are opposite on the extent of cell division (Table 5).

\section{Summary of B.a progeny interactions}

We conclude that the cells in each of the three types of B.a $(1 / \mathrm{r}) \times x$ cell pairs respond to cues provided by the other B.a progeny. For all pairs, the other B.a progeny act to promote the posterior fate. Specifically, ap, pa, and pp promote $\beta$ fate in the aa pair, and aa, ap, and pp promote $\zeta$ fate in the ap/pa pairs. B.a progeny ablation results in abnormal lineages in both cells of the pp pair. However, as discussed above, one function of aa, ap, and pa might be to promote posterior $(\delta)$ fate in the pp pair.

For each pair the interaction is unique. Any other pair of B.a progeny is sufficient to promote posterior fate $(\beta)$ in aa cells, whereas a single pair is not always sufficient to promote posterior fate $(\zeta)$ in pa cells. In the pp pair, only the pa cells are sufficient to promote both $\gamma$ and $\delta$ fates. At least one set of ap or pa cells is required to promote posterior fate $(\delta)$. The pa cells have two distinct roles. Ablation of the pa cells alone reduces the progeny of presumptive $\gamma$, whereas ablation of both the ap and pa cells increases the progeny of presumptive $\gamma$, compared to normal. These roles of the pa cells are discussed in Section III.C.

\section{Interactions among identified positional cues}

The ablation experiments described so far indicate that each pair responds to several positional cues. For each pair, most of these have distinct effects. To understand how the cues might combine to specify fate in each group, we examined animals in which we ablated two or more 'signals.' Such ablations can indicate the regulatory relationship among the cues and the nature of signal integration in the responding cells. We refer to ablation of single components (e.g., F and

\section{A Intact}

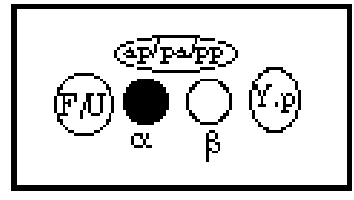

\section{B Singles}

(1)

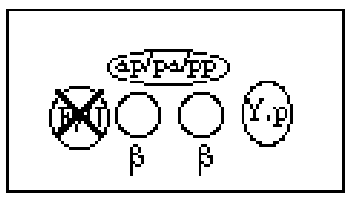

(2)

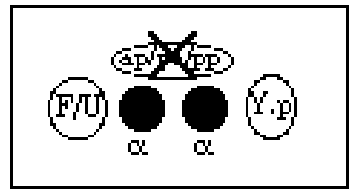

\section{Isolated pair}

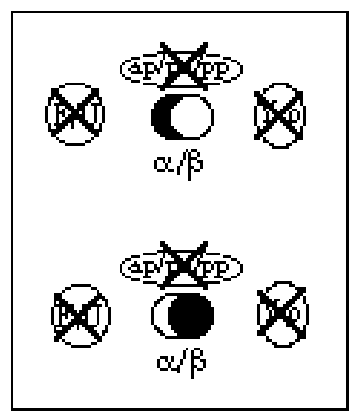

Fig. 11. Schematic summary of the effects of ablation of multiple positional cues on the aa cell pair. (B.1) Ablation of $F$ and $U$ results in both aa cells adopting the posterior $(\beta)$ fate (white circle). (B.2) Ablation of other B.a progeny results in both aa cells adopting the anterior $(\alpha)$ fate (black circle). (C) In the absence of all identified positional cues, aa cells fail to migrate, but often produce one $\alpha$-like and one $\beta$-like lineage. Anterior left, ventral down. Data of Table 1B.1;D.1 (B), and H.2 (C).

U) as a 'single' ablation, and ablation of two components (e.g., F and U, ap and pa and pp) as a 'double' ablation, even though multiple cells are removed.

\section{A. Ventral group (aa cells)}

Two major components of fate specification have been identified for the aa pair. $\mathrm{F}$ and $\mathrm{U}$ provide anterior positional cues because ablation of F/U disrupts presumptive $\alpha$ fate and results in (partial) transformation of $\alpha$ to $\beta$. The other B.a progeny, ap/pa/pp, promote posterior fate. Ablation of these cells disrupts presumptive $\beta$ fate and results in transformation of $\beta$ to $\alpha$. In addition, Y.p may play a minor role in providing posterior cues. To understand the interplay of these cues, we have followed the cell lineages of animals in which two or all three of these components have been ablated (key experiments summarized in Fig. 11).

\section{F/U and Y.p}

Analysis of ablations of F/U and Y.p is complicated by the fact that in most animals the aa cells remain left/right rather than migrate to anterior/posterior positions as they do in intact animals. Thus positionally there is no 'presumptive' $\alpha$ or $\beta$. Since neither F/U nor Y.p ablation alone results in such high frequency of failure to migrate, it suggests that both $\mathrm{F} / \mathrm{U}$ and Y.p (in the presence of all B.a progeny) are sufficient to promote normal migration. Thus, although Y.p ablation alone has only a minor effect on fate specification (see Table 2), it appears to play a role in anterior/posterior patterning. Despite the abnormal positioning, one can follow the lineages of the cells, and interpret them in terms 
of the lineages that those cells would normally produce. However, the division axes of the abnormally positioned cells are usually abnormal.

The aa cells in $\mathrm{F}^{-} \mathrm{U}^{-} \mathrm{Y} \cdot \mathrm{p}^{-}$animals can produce both $\alpha$ and $\beta$-like lineages, although some abnormal lineages are also observed ( $2 / 5$ animals abnormal, Table $1 \mathrm{G})$. In each of the three animals without abnormal lineages, one of the two aa cells produced an $\alpha$-like lineage, and the other produced a $\beta$-like lineage. Since $\alpha$ lineages were observed in $3 / 5 \mathrm{~F}^{-} \mathrm{U}^{-} \mathrm{Y} . \mathrm{p}^{-}$animals while no $\alpha$ lineages were observed in $7 \mathrm{~F}^{-} \mathrm{U}^{-}$animals, the removal of Y.p may partially counteract the absence of $F$ and $U$ in specification of fate. Thus although single ablation of Y.p results in only a minor disruption of fate in the aa cells, ablation of Y.p together with $\mathrm{F} / \mathrm{U}$ indicates that the aa cells can respond to Y.p cues.

\section{2. $F / U$, and ap/pa/pp}

Ablation of the two primary components of aa fate specification, F/U and ap/pa/pp, does not clearly resemble one or the other single ablation (Table 1H.1). As in the $\mathrm{F}^{-} \mathrm{U}^{-} \mathrm{Y} \cdot \mathrm{p}^{-}$double ablation, the aa cells tend to remain side by side, and some abnormal lineages are observed. In contrast to the single ablation of $\mathbf{a p} / \mathbf{p a} / \mathbf{p p}$, we observe many $\beta$-like lineages. Since the $\beta$ to $\alpha$ transformations that occur upon ap/pa/pp ablation are dependent on the presence of $\mathrm{F}$ and $\mathrm{U}$, one of the roles of the other B.a progeny may be to modulate (inhibit, regulate, or otherwise localize) the $\mathrm{F} / \mathrm{U}$ activity. However, the B.a progeny must also have an active role of their own, antagonistic to F/U, since the double ablation does not simply resemble the single ablation of F/U.

\section{F/U, Y.p, and ap/pa/pp}

Removal of all three components (F/U, Y.p, ap/pa/pp) isolates the aa pair from all characterized components of fate specification (Table 1H.2). The majority of the cells remain left/right (and thus first division axes are a-p rather than 1r), but both $\alpha$-like and $\beta$-like lineages are observed. In each animal, one cell produces four progeny suggesting it is $\alpha$ like, and the other cell produces six (or sometimes five) progeny, often in the $3+3$ pattern associated with the $\beta$ fate. Thus patterning of the two cells is apparent, although the cells do not migrate properly and the extracellular cues that we have identified are absent. There might be other factors that interact with the aa cells to promote their fates. However, since the aa cells remain side by side, these factors are unlikely to be providing anterior-posterior positional cues. A more satisfactory explanation is that the two aa cells interact with each other. In the presence of the cues provided by the other cells this lateral interaction may act to reinforce the positional information, to ensure the result of one cell with each fate. However, in the absence of those cues the cells can interact to establish one cell adopting an $\alpha$-like fate, and one a $\beta$-like fate.

\section{Interaction between aa cells}

\section{a. B.al- or B.ar- background}

To further characterize the possible role of interaction between the two aa cells in promoting fate, we have carried out a series of experiments in which a single aa cell remains in different ablation backgrounds (Table $1 \mathrm{~K}$ ). We eliminated one of the aa cells by ablating either the pre- cursor B.al or B.ar. These ablations also eliminate all of the other B.a progeny on one side. Although we have evidence that the other B.a progeny can play a role in $\alpha / \beta$ fate specification, in pairwise ablations their activity is redundant. In addition, all $\mathrm{B} . \mathrm{al}^{-}$or B.ar ${ }^{-}$animals have the same ablation background, so comparison among these experiments can provide some information about the contribution of interaction between aa cells in the specification of fate.

Ablation of B.al or B.ar leaves one aa daughter, but the other positional cues (from F/U, Y.p. and potentially from the remaining B.a progeny) are intact. Four of five of the aa cells in this case produce an $\alpha$ lineage (one abnormal). This result is consistent with the results of Sulston and White (1980), who found that if a single aa cell is ablated, the remaining cell will produce an $\alpha$ lineage. We find that ablation of $\mathrm{F}$ and $\mathrm{U}$ in a B.al ${ }^{-}$or B.ar ${ }^{-}$animal results in the single aa cell producing a $\beta$ lineage. Therefore, it is $\mathrm{F}$ and $U$ that promotes $\alpha$ fate in the single aa cell. In the absence of $\mathrm{F}$ and $\mathrm{U}$, the remaining B.a progeny and Y.p promote the $\beta$ fate. If both $\mathrm{F} / \mathrm{U}$ and Y.p are ablated in a B.al ${ }^{-}$or B.ar ${ }^{-}$background, the remaining aa cell still usually adopts the posterior fate (Table 1K.3), although the presence of the remaining B.a progeny is apparently not always sufficient to promote $\beta$ fate. We have not distinguished whether this is because Y.p is absent, or because the full set of B.a progeny is not present. Nevertheless, in general, single aa cells can respond to positional cues.

\section{b. Isolated B.a(I or r)aa}

We isolated single aa cells in five animals by removing F/U, Y.p, and all of the B.a progeny except for one of the aa cells (Table 1L.1). In four cases this cell underwent an $\alpha$-like lineage, and in one case it underwent a $\beta$-like lineage. Thus in the absence of all identified cues, aa cells generally adopt $\alpha$ fate. However, because of the variable results, we have not established $\alpha$ as the 'ground state'. Another possibility is that the 'isolated' aa cell chooses between $\alpha$ and $\beta$ fate stochastically.

\section{Summary of experiments in the ventral group}

Multiple cell interactions play a role in fate specification in the aa pair. F/U, ap/pa/pp, and Y.p contribute external cues to distinguish anterior and posterior fates, as well as to promote proper migration of the cells to an anterior/posterior orientation. This role in promotion of migration is apparent only if more than one component is removed, and is therefore redundant. The presence of any two of the three components is generally sufficient to promote normal migration, whereas the presence of any one is not. Double ablation experiments suggest that one role of the ap/pa/pp cells may be to localize the activity of $\mathrm{F}$ and $\mathrm{U}$. Isolation of the aa pair suggests that the two aa cells interact to specify fate or ensure that the cells each adopt a different fate. Experiments that leave a single aa cell indicate that single cells can respond to the identified positional cues, and that interaction between the aa cells is not required for the adoption or execution of $\alpha$ or $\beta$ fate. Isolation experiments, however, did not identify a 'ground state' for aa cells.

Our observations may be consistent with the hypothesis that $\alpha$ and $\beta$ lineages represent distinct precursor cell fates. The first division axis may not be critical since essentially 
normal $\alpha$ and $\beta$ division patterns are observed even if the aa cells remain side-by-side and the first division is along an anterior/posterior axis. Even if such lineages $\left(\alpha \tau, \beta_{\tau}\right)$ are considered normal, we have observed several other types of abnormal lineages produced by presumptive $\alpha$ and $\beta$ cells. Thus, other interpretations of the data are possible. However, we reject the simple hypothesis that the fate is independently specified in the aa cell daughters. Specifically, in one type of abnormal aa lineage ('abn-5'), the aa cell generates one daughter that produces 2 progeny (like $\alpha$ ), and one that produces 3 progeny (like $\beta$ ). These lineages are sometimes observed in animals where the ablation results in the aa cells remaining lateral, rather than migrating to the midline. Since the first axis of division in these cells is usually anterior/posterior, as opposed to the normal left/right, this places one daughter of each cell in the anterior position (normally occupied by $\alpha .(1 / \mathrm{r})$ ), and the other daughters in the posterior position $(\beta .(1 / \mathrm{r})$ environment). Nevertheless, lineages with both aa cells executing abn-5 lineages (e.g., 2 progeny from the anterior daughter, 3 progeny from the posterior daughter) are rare (1/64 of all animals with abnormal lineages; 1/19 of animals where aa cells remain left/right). In addition, many abn-5 lineages show $\beta$-like timing in the division of both aa daughters, but fail to execute the final division on one side, rather than showing $\alpha$-like timing in the daughter with $\alpha$-like divisions and $\beta$-like timing in the daughter with $\beta$-like divisions. It is possible that the abn-5 lineages might simply be abortive $\beta$ lineages. In addition to these intermediate lineages, we also observe lineages in which an aa cell produces more than six progeny or an abnormal pattern of six progeny $(4+2$ rather than $3+3$ ). These lineages, which represent $14 \%$ of

\section{A Intact}

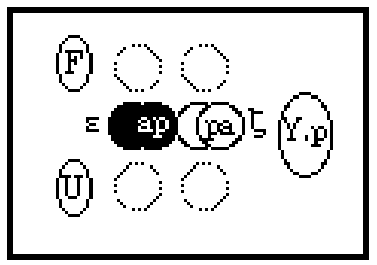

B

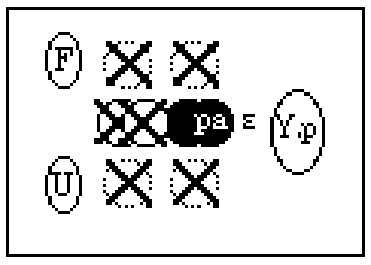

C Isolated Cells

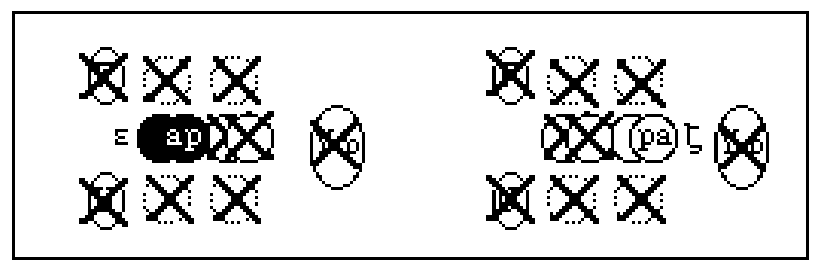

Fig. 12. Schematic summary of the effects of ablation of multiple positional cues on the ap/pa cell pairs. In intact animals, ap cells always adopt $\varepsilon$ fate, and pa cells adopt $\zeta$ fate (A). If other B.a progeny are ablated, pa cells adopt $\varepsilon$ fate (B). This transformation of fate is dependent on the presence of F/U. In the absence of identified positional cues, ap cells will usually adopt $\varepsilon$ fate, and pa cells will adopt $\zeta$ fate. Anterior left, ventral down. Data of Table 1F.1 (B) and L.3,4 (C). abnormal aa lineages, suggest that the progeny of the aa cells may be somewhat responsive to extracellular cues.

\section{B. Lateral groups (ap/pa cells)}

A summary of the interactions affecting the ap/pa pairs is shown in Fig. 12. Ablation of F and $U$ can sometimes disrupt the fate of the anterior ap cells. Ablation of all of the B.a progeny except for the pa cells transforms these cells from their normal $\zeta$ fate to $\varepsilon$ fate (see Fig. 9B.2). We observed no disruption of fates in these pairs after ablation of Y.p. The $\mathrm{F}^{-} \mathrm{U}^{-} \mathrm{Y} . \mathrm{p}^{-}$animals have a slight but not significant enhancement of the $\mathrm{F}^{-} \mathrm{U}^{-}$effect on the ap cells (compare Table 1B.1 with G). However, the fate of the pa cells is still not appreciably disrupted.

How do these positional cues interact with the cues from the other B.a progeny? The $\zeta$ to $\varepsilon$ transformation observed in $\mathbf{a a}^{-} \mathbf{a p}^{-} \mathbf{p p}^{-}$(B.a(l/r)a $\mathrm{a}^{-}$B.a(l/r)pp ${ }^{-}$) animals is dependent on the presence of $F$ and $U$ (Table 1L.3). Although we have not examined $\mathrm{F}^{-} \mathrm{U}^{-} \mathrm{B} \cdot \mathrm{a}(\mathrm{l} / \mathrm{r}) \mathrm{a}^{-} \mathrm{B} \cdot \mathrm{a}(\mathrm{l} / \mathrm{r}) \mathrm{pp}^{-}$animals specifically, Y.p does not appear to play a role in pa fate specification. $\mathrm{F}^{-} \mathrm{U}^{-} \mathrm{Y} \cdot \mathrm{p}^{-} \mathrm{B} \cdot \mathrm{a}(\mathrm{l} / \mathrm{r}) \mathrm{a}^{-} \mathrm{B} \cdot \mathrm{a}(\mathrm{l} / \mathrm{r}) \mathrm{pp}^{-}$ablation isolates the pa cells (one on each side), and these cells produce $\zeta$ lineages. Thus in the absence of $F$ and $U$, pa cells do not require the other $\mathrm{B}$.a progeny to adopt the $\zeta$ fate. In contrast, an $\mathrm{F}^{-} \mathrm{U}^{-} \mathrm{Y} \cdot \mathrm{p}^{-} \mathrm{B} \cdot \mathrm{a}(\mathrm{l} / \mathrm{r}) \mathrm{p}^{-} \mathrm{B} \cdot \mathrm{a}(\mathrm{l} / \mathrm{r}) \mathrm{aa}^{-}$ablation isolates the ap cells, and these cells usually produce $\varepsilon$ lineages (Table 1L.4).

Both the ap and the pa cells exhibit plasticity in fate specification. Indeed, since the pa cells can adopt the fate normally associated with ap, the pairs have some characteristics that might indicate that they form equivalence groups. However, in the absence of all identified cells that influence pa and ap cell fate, the ap and the pa cells exhibit distinct fate differences. Thus, either there are as yet unidentified positional cues that somehow distinguish the two cell types, or these cells have distinct fate potentials due to their lineal history.

For the ap and pa cells, many ablations that result in a disruption of normal fates result in a complete transformation of cell fate. In intact animals, differences between $\varepsilon$ and $\zeta$ lineages are apparent soon after division of ap and pa cells (see Fig. 10). Under experimental conditions, $85 \%$ of ap/pa cells with disrupted fate produced either $\varepsilon$ or $\varepsilon^{*}$ lineages $\left(24 / 46\right.$ were $\varepsilon^{*}, 15 / 46$ were $\varepsilon$ ). Since $\varepsilon^{*}$ lineages are not observed in intact animals, $\varepsilon^{*}$ may be an abnormal $\varepsilon$ (or $\zeta$ ) lineage, rather than a distinct 'fate' of its own. However, transformations from $\zeta$ to $\varepsilon$ lineages in pa cells are apparent in the first division, and are generally complete transformations. The early evidence of fate choice (size and division timing of ap/pa cell daughters), along with the high percentage of fate disrupted cells that produce one of three distinct lineages, is consistent with a hypothesis of early commitment to one of a defined set of potential fates. However, it may also simply reflect the relatively simple role of positional cues in the specification of the ap/pa fates.

\section{Dorsal group (pp pair)}

We have identified four distinct activities that are involved in the specification of fate in the pp pairs: F/U, Y.p, pa, $\mathbf{a p} / \mathbf{p a} /(\mathbf{a a})$. Ablation of either $\mathrm{F} / \mathrm{U}$ or the pa cells results in 


\section{A Intact}

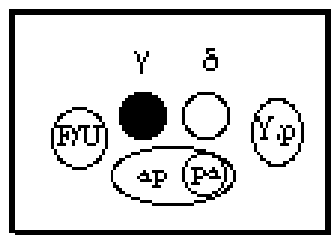

\section{Isolated Pair}

B Singles

(1)

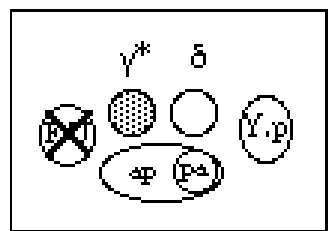

(2)

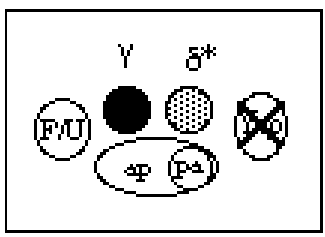

(3)

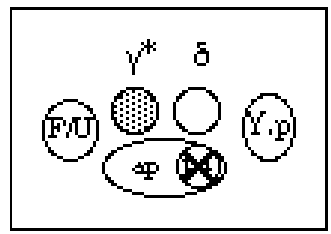

(4)

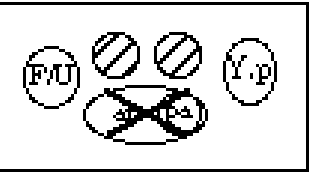

(1)

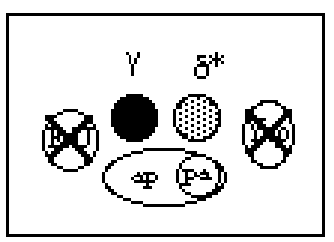

(2)

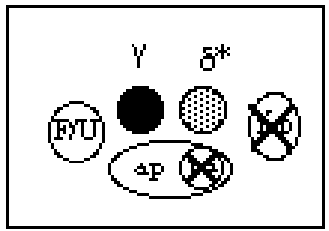

\section{Doubles}

(3)

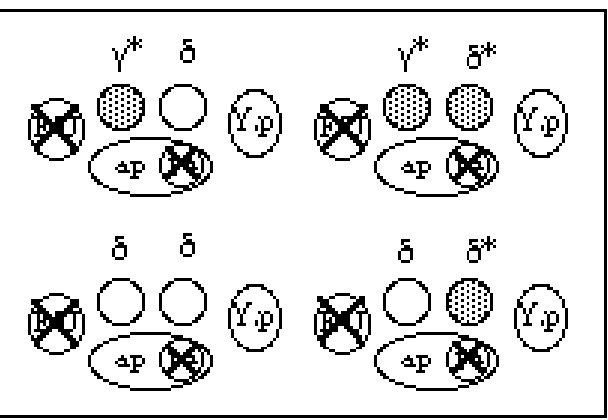

(4)

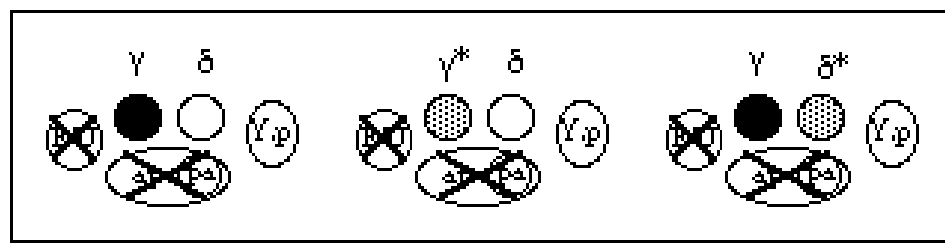

Fig. 13. Schematic summary of the effects of ablation of multiple positional cues in the pp cell pair. (B.1) Ablation of F/U results in truncated anterior (presumptive $\gamma$ ) lineages. (B.2) Ablation of Y.p results in extra divisions of posterior (presumptive $\delta$ ) cells. (B.3) Ablation of pa cells results in truncated anterior lineages. (B.4) Ablation of ap/pa/(aa) results in abnormal proliferative lineages in both anterior and posterior pp cells. (C.1) Ablation of F/U and Y.p resembles Y.p ablation, although presumptive $\gamma$ lineages may also be disrupted. (C.2) Ablation of pa and Y.p resembles Y.p ablation. (C.3) Ablation of F/U and pa randomizes the polarity of pattern. (C.4) Ablation of $\mathrm{F} / \mathrm{U}$ and $\mathbf{a p} / \mathbf{p a} /(\mathbf{a a})$ results in variable lineages, but reinstatement of pattern polarity. (D) Removal of all four identified positional cues (F/U, Y.p, pa, ap/pa/(aa)) results in abnormal proliferation of both presumptive $\gamma$ and $\delta$. Anterior left, ventral down. Data of Table 1B.1, C.1, E (B); G, I.1-4 (C); I.6,7 (D).

truncation of presumptive $\gamma$ lineages, so we infer that these cells promote anterior fate in some way. Ablation of Y.p results in extra divisions of presumptive $\delta$, and ablation of ap/pa/(aa) results in extra divisions of both presumptive $\gamma$ and $\delta$. Thus Y.p and ap/pa/(aa) promote posterior fate, or otherwise inhibit proliferation. To understand how each of these four components exerts its effect, we have followed the $\mathrm{B}$ cell lineage in animals after ablation of two, three, or all four components (Fig. 13).

\section{F/U and Y.p}

$\mathrm{F} / \mathrm{U}$ and Y.p provide positional information from outside of the B.a progeny group (Fig. 13B.1,2). Ablation of both $\mathrm{F} / \mathrm{U}$ and Y.p results in extra divisions of the presumptive $\delta$ cell, and occasionally abnormal presumptive $\gamma$ lineages (Fig. 13C.1; data of Table 1G). Thus, the double ablation resembles the single Y.p ablation (although the fate of pre- sumptive $\gamma$ is not always normal). Therefore, one of the roles of $\mathrm{F} / \mathrm{U}$ might be to counteract (modulate) the posterior-promoting activity of Y.p on presumptive $\gamma$. This activity of $\mathrm{F} / \mathrm{U}$ is required only in the presence of Y.p. However, while $\mathrm{F}$ and $\mathrm{U}$ likely have other roles (see below), these experiments indicate that $\mathrm{F}$ and $\mathrm{U}$ are not necessary for a normal $\gamma$ lineage. In $\mathrm{F}^{-} \mathrm{U}^{-} \mathrm{Y} . \mathrm{p}^{-}$animals, in contrast to the aa cells, the pp cells still migrate to their normal anterior/posterior positions. Furthermore, the fact that the anterior cell generally produces a $\gamma$ lineage and the posterior cell a $\delta^{*}$ lineage indicates that removal of both identified positionally anterior and posterior sources of cues is not sufficient to eliminate anterior/posterior patterning in this pair.

\section{Y.p and pa}

Ablation of the pa cells results in truncation of presump- 
tive $\gamma$ lineages, and ablation of Y.p results in extra divisions of the presumptive $\delta$ cell (Fig. 13B.2,3). In the pp pair, the double Y.p. $\mathbf{p a}^{-}$animals resemble Y.p ${ }^{-}$animals (Fig. 13C.2; data of Table 1 I.1). Thus, one of the roles of the pa cells is to inhibit Y.p activity from influencing the fate of the presumptive $\gamma$ cell. This function is only required if Y.p is present. In addition, this experiment suggests how the positionally posterior pa cells can act to promote an anterior fate. The position of the pa cells (see Figs 3E, 4B.2) suggests this role may be 'passive.' Specifically, the pa cells may physically block the activity of Y.p from reaching the presumptive $\gamma$ cell. This proposed mechanism does not require that the pa cells be biochemically distinct from the other B.a progeny, although it also does not rule out this possibility.

\section{F/U and pa}

Single ablations of either $\mathrm{F} / \mathrm{U}$ or pa result in intermediate and variable disruption of presumptive $\gamma$ lineages (Fig. 13B.1,3). To establish whether complete transformations from the $\gamma$ to the $\delta$ fate could be achieved by removal of both components, we characterized $\mathrm{F}^{-} \mathrm{U}^{-} \mathbf{p a}^{-}$animals (Fig. 13C.3; data of Table 1 I.2). While this double ablation does not result in an increased frequency of complete $\gamma$ to $\delta$ transformations, the normal pattern of anterior/posterior polarity is disrupted. In either $\mathrm{F}^{-} \mathrm{U}^{-}$or $\mathbf{p a}^{-}$animals, the fate of presumptive $\delta$ is not disrupted, whereas presumptive $\gamma$ lineages are often truncated. Thus, two patterns are observed: normal polarity and apolar. In contrast, double ablation of $\mathrm{F} / \mathrm{U}$ and pa can result in a fate disruption of both presumptive $\gamma$ and $\delta$ cells. In addition, we observe all possible classes of pattern: normal polarity, apolar, and reversed polarity.

\section{F/U and ap/pa/(aa)}

Single ablation of $\mathbf{a p} / \mathbf{p a} /(\mathbf{a a})$ results in novel lineages and abnormal proliferation of presumptive $\gamma$ and $\delta$, whereas ablation of $\mathrm{F} / \mathrm{U}$ results in truncated lineages produced by the presumptive $\gamma$ cell (Fig. 13B.1,4). The double ablation of $\mathrm{F} / \mathrm{U}$ and $\mathbf{a p} / \mathbf{p a}$ or $\mathbf{a p} / \mathbf{p a} / \mathbf{a a}$ (considered together as $\mathbf{a p} / \mathbf{p a} /(\mathbf{a a}))$ has allowed us to determine whether the excessive proliferation results in part from inappropriate modulation of $\mathrm{F} / \mathrm{U}$ information. In $\mathrm{F}^{-} \mathrm{U}^{-} \mathbf{a p}-\mathbf{p a}^{-}\left(\mathbf{a a}^{-}\right)$animals, lineages of presumptive $\gamma$ and $\delta$ do not closely resemble those seen in either the single $\mathrm{F}^{-} \mathrm{U}^{-}$or $\mathbf{a p}^{-} \mathbf{p a}^{-}\left(\mathbf{a a}^{-}\right)$animals (Fig. 13C.4; data of Table 1 I.3,4). Proliferative lineages are not observed. Although many of the lineages are slightly abnormal, we only observe the more common lineages: normal $\gamma$ and $\delta$, and $\gamma^{*} / \delta^{*}$. However, the presence of Y.p is not sufficient to ensure $\delta$ fate in the posterior cell. Disruption of both anterior and posterior fates is observed, although not in the same animal. In Section II.C we proposed that the ap/pa/(aa) cells have two functions: promotion of posterior fate $(\delta)$ and promotion of proper execution of the $\gamma$ lineage. The double ablation result indicates that $\mathrm{F} / \mathrm{U}$ may likewise act at two steps: promotion of anterior fate $(\gamma)$ and execution of $\gamma$ lineage. We hypothesize that one role of the $\mathrm{F} / \mathrm{U}$ activity for $\gamma$ fate execution is to promote pp proliferation. The ap/pa/(aa) cells counteract this activity, thus localizing it to $\gamma . \mathrm{a}$ (or $\gamma . \mathrm{a}(\mathrm{l} / \mathrm{r})$ ). Since removal of both $\mathrm{F} / \mathrm{U}$ and $\mathbf{a p} / \mathbf{p a} /(\mathbf{a a})$ results in more normal lineages than either single ablation, we conclude that $\mathrm{F} / \mathrm{U}$ and $\mathbf{a p} / \mathbf{p a} /(\mathbf{a a})$ act antagonistically and in parallel on the same process(es).

One consistent characteristic among $\mathrm{F}^{-} \mathrm{U}^{-} \mathbf{a p}^{-} \mathbf{p a}^{-}\left(\mathbf{a a}^{-}\right)$ animals is that the fate of the positionally anterior pp cell is relatively more 'anterior' than the fate of the positionally posterior pp cell; the pair exhibits polarity of pattern. In other words, anterior/posterior polarity, which is lost in $\mathrm{F}^{-} \mathrm{U}^{-} \mathbf{p a}^{-}$animals, is regained by the additional ablation of the ap (compare Fig. 13C.3 with C.4). Y.p, the posteriorpromoting cell, can promote polarity in the pp pair in the absence of $\mathrm{F} / \mathrm{U}$ and $\mathbf{a p} / \mathbf{p a} /(\mathbf{a a})$. Since polarity can be disrupted in $\mathrm{F}^{-} \mathrm{U}^{-} \mathbf{p a}^{-}$animals, the presence of ap must somehow counteract this activity of Y.p.

\section{F/U, Y.p, and ap/pa/(aa)}

We have removed all of the identified components that specify fate in the pp pair (Fig. 13D). As with the aa pair, this isolation may allow identification of potential interaction between pp cells. The normal lineages and patterning observed in $\mathrm{F}^{-} \mathrm{U}^{-} \mathbf{a p}^{-} \mathbf{p a}^{-}\left(\mathbf{a a}^{-}\right)$animals are lost with the removal of Y.p (Table 1 I.6,7). A variety of proliferative lineages are observed from both presumptive $\gamma$ and $\delta$. Although there is no appreciable difference between presumptive $\gamma$ and presumptive $\delta$, proliferation may be less than in $\mathbf{a p}^{-} \mathbf{p} \mathbf{a}^{-}\left(\mathbf{a a}^{-}\right)$animals. Thus, without the identified cues, no polarity or evidence for interaction between the pp cells is readily apparent. However, the lineages are abnormal and variable enough that they are not easily interpreted.

A difference between the aa and pp cells is that the pp cells generally migrate to anterior/posterior positions even in the absence of the identified extracellular cues. Although this may indicate that anterior/posterior patterning cues for the pp cells may still be present, it may also reflect a difference in the physical environments within which the two pairs reside. The ventral area (aa environment) is relatively smaller and more crowded than the dorsal area (pp environment). Thus, in the absence of positional cues the aa cells might not be able to migrate medially, whereas the pp cells can. We cannot, however, rule out the possibility that additional cues exist for pp cells.

\section{Interaction between pp cells}

\section{a. B.al- or B.ar background}

Isolation of both pp cells did not provide direct evidence that they interact with each other to specify their fates. However, we have also characterized the lineages of single pp cells obtained after ablation of the precursor B.al or B.ar (Table $1 \mathrm{~K}$ ). Four of five single pp cells obtained by ablation of B.al or B.ar produced a $\gamma$ lineage, whereas one produced a $\delta$ lineage. Thus, interaction between pp cells is not essential to produce either normal $\gamma$ or $\delta$ fates. In these animals, it is possible that choice between the two fates is related to the relative anterior-posterior positioning of the single pp cell in the normal pp environment. Adoption of the $\gamma$ fate, however, is dependent on the presence of $F$ and U. Remaining pp cells in $\mathrm{F}^{-} \mathrm{U}^{-}$[B.al ${ }^{-}$or B. $\left.\mathrm{ar}^{-}\right]$animals produce $\delta$ lineages $(5 / 7)$ or $\gamma^{*} / \delta^{*}$ lineages (2/7). Likewise, the $\delta$ fate is dependent on the presence of Y.p. Single pp cells in $\mathrm{F}^{-} \mathrm{U}^{-} \mathrm{Y} . \mathrm{p}^{-}\left[\mathrm{B} \cdot \mathrm{al}^{-}\right.$or B.ar ${ }^{-}$animals produce $\gamma^{* / \delta^{*}}$ $\left(3 / 4 \gamma^{*} / \delta^{*} ; 1 / 4\right.$ abn-3) lineages. We do not believe this 
effect is merely the result of fewer neighbors (or more debris), because even single isolated pp cells can produce $\gamma$ lineages (see below). These observations are consistent with the proposed roles of F/U and Y.p in promoting $\gamma$ and $\delta$ fates, respectively.

Loss-of-function mutations in $l i n-12$, a gene known to play a role in the interactions between cells in other equivalence groups, result in $\delta$ to $\gamma$ fate transformations (Greenwald et al., 1983). This observation implies that the pp cells do interact, by analogy to other lin-12-dependent equivalence groups. Although isolation of the two pp cells did not offer evidence to support this hypothesis, comparison of $\mathrm{F}^{-} \mathrm{U}^{-} \mathrm{Y} . \mathrm{p}^{-}$to $\mathrm{F}^{-} \mathrm{U}^{-} \mathrm{Y} \cdot \mathrm{p}^{-}\left[\mathrm{B} . \mathrm{al}^{-}\right.$or B.ar $\left.{ }^{-}\right]$animals is suggestive. Specifically, the single pp cells in $\mathrm{F}^{-} \mathrm{U}^{-} \mathrm{Y} \cdot \mathrm{p}^{-}\left[\mathrm{B} \cdot \mathrm{al}^{-}\right.$or B.ar ${ }^{-}$animals do not produce $\gamma$ lineages $(0 / 4$ are $\gamma)$, whereas in $\mathrm{F}^{-} \mathrm{U}^{-} \mathrm{Y} \cdot \mathrm{p}^{-}$animals, where both pp cells are present, the anterior cell generally will produce a $\gamma$ lineage (4/5). Although these animals also differ in the total number of B.a progeny present, we suggest that the $\gamma$ fate in the $\mathrm{F}^{-} \mathrm{U}^{-} \mathrm{Y} . \mathrm{p}^{-}$animals may result from interaction between the two pp cells. If the pp cells do interact, it is possible that the interaction is not apparent in $\mathbf{a p}^{-} \mathbf{p a}^{-}\left(\mathbf{a a}^{-}\right)$animals because the $\mathbf{a p} / \mathbf{p a} /(\mathbf{a a})$ cells are necessary either for this interaction to occur, or for all aspects of the fates to be properly executed.

\section{b. Isolated B.a(I or r)pp}

After ablation of F/U, Y.p, and all B.a progeny except a single pp cell, we observed $\gamma$-like lineages in two of five animals, and abnormal proliferative lineages in three of five animals (Table 1L.2). We conclude that a pp cell requires positional cues to adopt the correct fate. Although the isolated fate can be $\gamma$-like, extracellular cues are apparently required to reliably ensure that the fate is properly executed. As is the case for isolated aa cells, there is no clear 'ground state' for the pp cells.

\section{Summary of experiments in the dorsal group}

The results of our removal of identified components of fate specification for the pp pair suggest how some of the cues may interact. The pa cells likely promote anterior fate by inhibiting or localizing the activity of Y.p, and the ap cells likewise may inhibit or localize the activity of $F / U$. One of the roles of $\mathrm{F}$ and $\mathrm{U}$ is to counteract Y.p. However, $\mathrm{F}$ and $\mathrm{U}$ have additional roles in the promotion of fate. For instance, comparison of $\mathbf{a p}^{-} \mathbf{p a}^{-}\left(\mathbf{a a}^{-}\right)$to $\mathrm{F}^{-} \mathrm{U}^{-} \mathbf{a p}^{-} \mathbf{p a}^{-}\left(\mathbf{a a}^{-}\right)$ animals, both of which have Y.p intact, suggests that $\mathrm{F}$ and $\mathrm{U}$ play a role in producing the abnormal, proliferative lineages. Likewise, although $\mathrm{F}$ and $\mathrm{U}$ are not required for the production of $\gamma$ lineages in $\mathrm{F}^{-} \mathrm{U}^{-} \mathrm{Y} . \mathrm{p}^{-}$animals, in a [B.al ${ }^{-}$ or B.ar ${ }^{-}$background, $\gamma$ lineages are only seen if $F$ and $U$ are present.

In most experimental animals the cells move roughly anterior/posterior relative to each other, as in intact animals. This movement allows the additional analysis of patterning and polarity within the pp pair. Removal of the positionally anterior and posterior F/U and Y.p cells still results in normal polarity within the pp pair. Thus either additional, unidentified cues can establish this polarity, or polarity information can come from the other B.a progeny. Analysis of $\mathrm{F}^{-} \mathrm{U}^{-} \mathbf{p a}^{-}$animals suggests that the latter explanation may indeed be the case, since the pattern appears random in these animals. However, polarity is restored after removal of the ap cells in this background. Therefore positional cues are not absent in the $\mathrm{F}^{-} \mathrm{U}^{-} \mathbf{p a}^{-}$animals, but they are either inhibited or somehow equally balanced. There is no obvious polarity in $\mathrm{F}^{-} \mathrm{U}^{-} \mathrm{Y} \cdot \mathrm{p}^{-} \mathbf{a p}^{-} \mathbf{p a}^{-}\left(\mathbf{a a}^{-}\right)$animals. However, the abnormality of the resultant lineages makes it difficult to score polarity.

Although there is some evidence for lateral interactions between the pp cells, the ablation results are less conclusive in the pp pair than in the aa pair. Experiments that include a single pp cell suggest that interaction between the pp cells is not necessary for the specification of $\gamma$ and $\delta$ fates, and isolation of the pp pair does not provide evidence that the homologues interact. However, in $\mathrm{F}^{-} \mathrm{U}^{-} \mathrm{Y} \cdot \mathrm{p}^{-}$animals $\gamma$ lineages are observed if both pp cells remain, but not if only one remains, suggesting that the two pp cells may have the potential to interact.

In contrast to our initial hypothesis, we believe that specification of pp lineages involves two steps based on (1) the nature of the $\gamma^{*} / \delta^{*}$ lineages, and (2) the existence of the abnormal proliferative lineages. The aspects of pp cell fate that we have used in our analysis are the axis of pp cell division (sagittal versus transverse; see Table 1 legend) and the number of progeny produced by each pp cell. Consid ering these criteria, $\delta^{*}$ lineages include characteristics of both $\gamma$ and $\delta$ lineages: the initial division is transverse $(\delta$ like), but each cell divides again. Thus the pp division axis can be uncoupled from the number of progeny produced. Similarly, $\gamma^{*}$ lineages have an initial sagittal division (like normal $\gamma$ lineages), but only two rounds of division. In abnormal proliferative lineages the pp cell produces up to eight progeny. Although the first division of an abnormal proliferative lineage is often sagittal ( $\gamma$-like), the axes and timing of divisions and the placement of progeny are highly variable. We propose that these abnormal types of lineages reflect two steps in lineage specification: an earlier step (possibly reflected in division axis) and a later step (reflected in proliferation). This two step process model of lineage specification distinguishes the pp pair because it suggests that $\gamma$ and $\delta$ fates do not result from the simple choice and execution of distinct sublineages, but rather a series of decisions influenced by extracellular cues. Thus although $\gamma$ and $\delta$ are distinct pp fates, they do not represent distinct sublineages.

\section{Differences between B.a(l/r)a and B.a(l/r)p}

Our ablation results suggest that there is a fundamental difference in fate potential between the aa pair and the pp pair. For instance, single isolated aa cells generally produce $\alpha$ like lineages (average number of progeny $=4.4$ ), whereas single isolated pp cells generally produce more proliferative and variable lineages (av. prog.=6.2). The cells also respond differently in the same ablation backgrounds. In addition, although the siblings of the aa cells (ap) and the siblings of the pp cells (pa) can respond to extracellular cues, the behavior of these cells when isolated from the identified cues suggests that they may also be inherently different from one another. Specifically, isolated pa cells produce $\zeta$ lineages, and isolated ap cells generally produce $\varepsilon$ lineages, the fates associated with these cells in intact animals. Since we now 

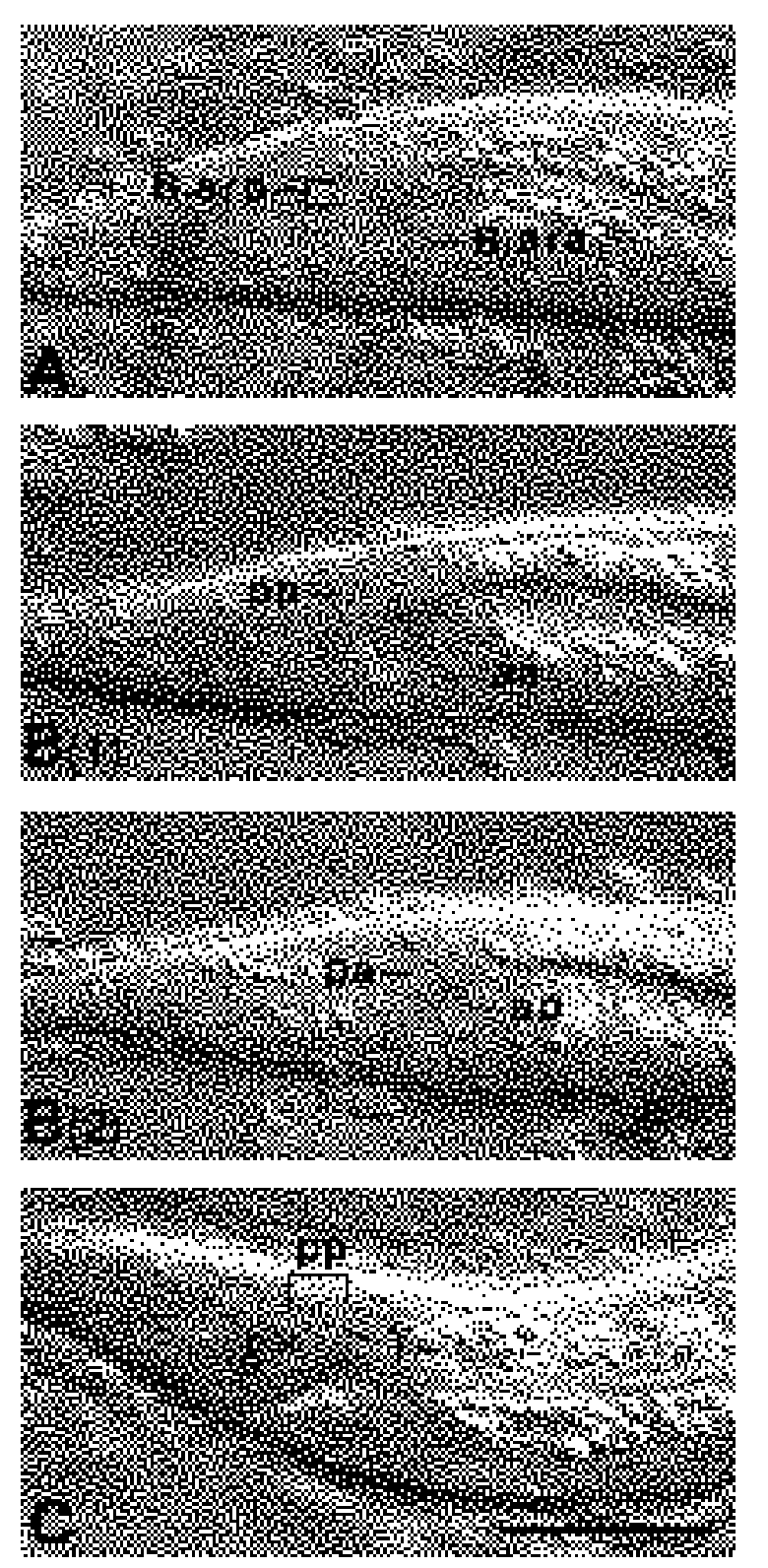

Fig. 14. Nomarski photomicrographs illustrating (A) the difference between B.arp and B.ara in timing of cell division and $(\mathrm{B}, \mathrm{C})$ the migration of the $8 \mathrm{~B}$.a progeny. Anterior is to the right, ventral down (right lateral view). (A) B.arp divides prior to B.ara (B) After both B.a(1/r)a and B.a(l/r)p have divided, B.a(1/r)aa and B.a(l/r)pp are positioned left/right prior to migration (B.1; compare with Fig. 4B.1) and B.a(1/r)ap and B.a(1/r)pa are approximately dorsal/ventral (B.2; compare with Fig. 4B.2). The cells then migrate to their anterior/posterior positions. The pp cells are migrating (C). In this animal, B.arpp will be $\gamma$, and B.alpp will be $\delta$. Scale bar, $20 \mu \mathrm{m}$.

have a handle on some of the conditional components of fate, we can consider what may reflect an autonomous component of fate specification for these cells.

A simple event that could account for the inherent difference(s) between the aa and pp cells, and between the ap and pa cells, is that a difference in fate is established between the precursors B.a(1/r)a and B.a(1/r)p. We have
Table 6. Bilateral symmetry in $\alpha / \beta$ and asymmetry in $\gamma / \delta$ fates

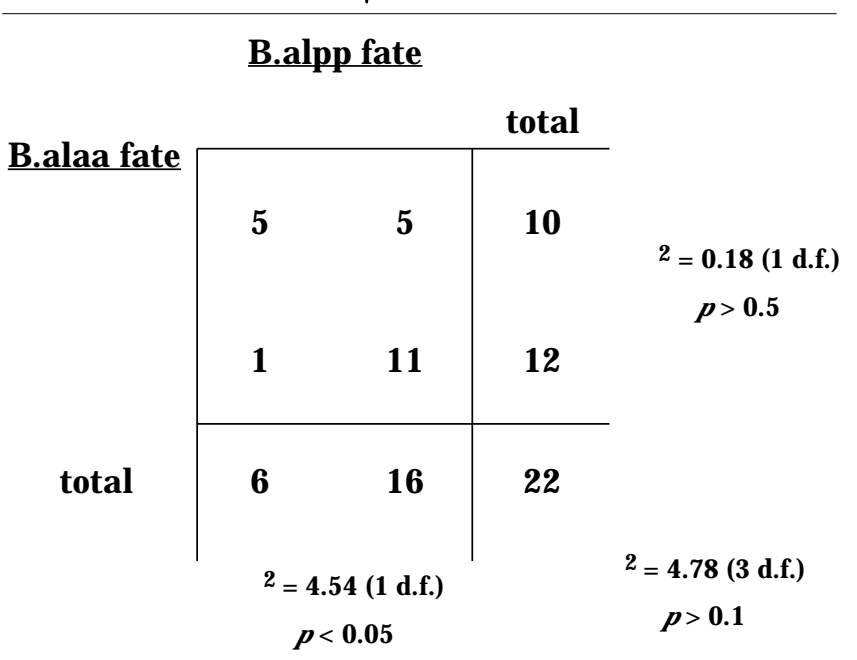

The table indicates the fate of the left cell observed through migration of the aa and pp cells. For instance, of 22 animals observed, in 11, B.alpp adopts the posterior position $(\delta)$ and B.alaa adopts the posterior position ( $\beta$ ) (implicitly, B.arpp adopts the anterior position $(\gamma)$ and B.araa adopts the anterior position $(\alpha)$ in these animals). $\chi^{2}$ calculated for $\mathbf{p p}$ and aa fates independently, and dependently. Fate choice in the aa pair is random. Fate choice in the pp pair is skewed. B.alpp was observed to adopt the posterior position $73 \%$ of the time. Fate choice in the aa pairs is independent of $\mathbf{p p}$ choice.

closely examined the behavior of these cells to identify whether there are any observable differences that would be consistent with this hypothesis. Analysis of the timing of the division of the B.a( $1 / \mathrm{r}) \mathrm{a}$ and $\mathrm{B} \cdot \mathrm{a}(\mathrm{l} / \mathrm{r}) \mathrm{p}$ cells suggests that the two pairs of cells, although morphologically similar, have acquired observable differences by this stage. Specifically, B.a(1/r)p always divide prior to B.a(1/r)a (mean time difference $=16$ minutes $(n=22)$, Fig. 14A). Although in rare cases (3/44 sides) a posterior cell divides at about the same time as the anterior cells, they never divide after the anterior cells. One component of cell state - timing of division - clearly differs between the B.a(l/r)a and B.a(1/r)p cells, and thus the precursors of the aa and pp cells are distinct. These results are consistent with the observations of Sulston and Horvitz (1977) and Sulston et al. (1980).

The animals examined for timing of $\mathrm{B} . \mathrm{a}(\mathrm{l} / \mathrm{r}) \mathrm{a}$ and B.a(l/r)p divisions were also observed through the migration of the B.a(1/r)xx cells (Fig. 14 B, Table 6). Our results suggest that although both left and right pp cells can adopt the anterior position, the probabilities are not equal: B.arpp adopted the anterior position (and $\gamma$ fate) 16/22 times (73\%). The biological relevance of this apparent bias is not clear. aa cells adopted anterior and posterior positions randomly, and there is no correlation between anterior/posterior choice adopted by the aa pair and the pp pair.

\section{DISCUSSION}

\section{Multiple cell interactions specify B.a(I/r)xx fates: a model}

We have characterized fate specification in three distinct 


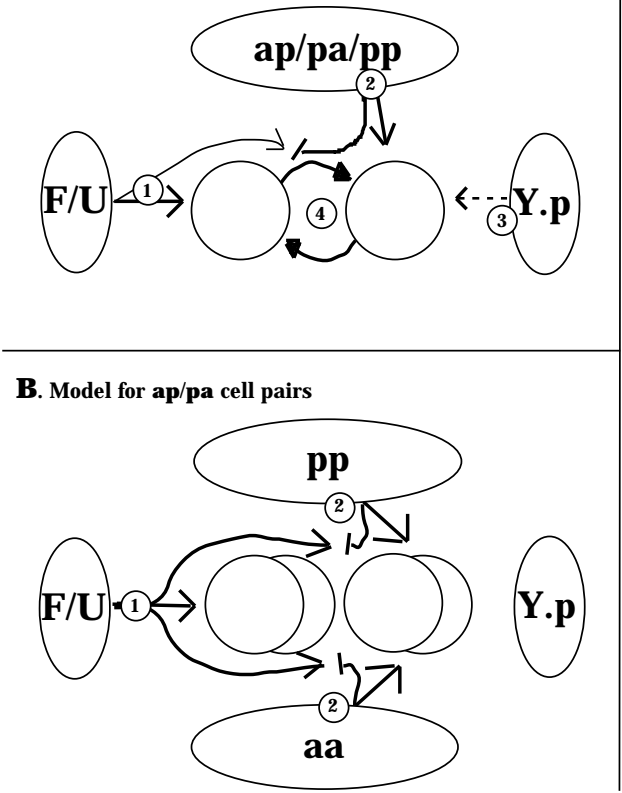

C. Two step model for pp cell pair 1. First step
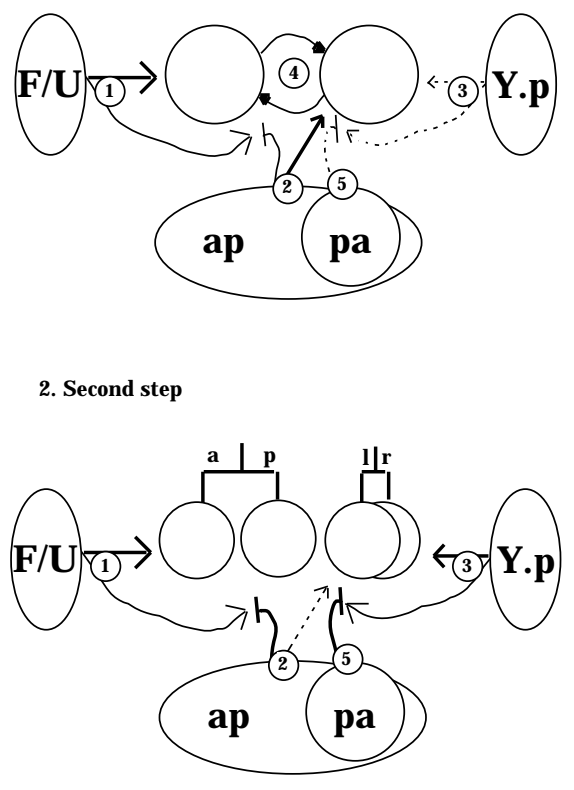

Fig. 15. A model for fate specification in the three cell pair types (anterior left, ventral down). Refer to text for more complete discussion. Positional cues and lateral interactions indicated with arrows. Modulatory interactions indicated with bars. Dashed lines indicate a weaker effect. In general the B.a progeny are indicated to have two effects (function both as a positional cue and a modulator).

This may reflect their potential role as 'insulators' as well as providers of an active positional cue. The relative requirement for each function may be different in each of the three pairs. (A) In the aa pair, F/U (1), B.a progeny (2), and possibly Y.p (3) provide positional cues. The other B.a progeny (2) modulate $\mathrm{F} / \mathrm{U}$ information (shown as blocking F/U cue). The two aa cells also interact with each other (4). This model does not take into account the possibility of later interactions required for

maintenance of fate choice. (B) In the ap/pa pairs, F/U (1) and possibly the other B.a progeny (2) provide positional cues. The B.a progeny may modulate or localize cues from F/U (2). (C) A two step model for the pp pair. In the first step, F/U (1) and the B.a progeny (2) provide positional cues. The B.a progeny may act to modulate F/U activity (2). The two pp cells may also interact with each other (4). We envision that the second step of fate specification occurs in the progeny of the pp cells. In this step, F/U (1) and Y.p (3) (and possibly the B.a progeny (2)) provide positional cues. The other B.a progeny regulate F/U (2) and Y.p (5) information, and F/U may modulate Y.p information (not included in Fig.). Note that some components of the two steps may temporally or functionally overlap. As drawn, the models indicate that interactions take place at the $\mathrm{B}=10$ cell stage for the aa pair (A) and the ap/pa pairs (B). This is consistent with the data, although the possibility that interactions occur later cannot be ruled out. Likewise, the timing of fate specification in the two step model for pp cells (C) is consistent with the data, but not the only possibility. We have interpreted the results in terms of promotion and transformation of distinct fates. However, a more conservative interpretation which considers only whether a lineage is disrupted (such as in Tables 3, 4, and 5) yields a similar model. We have not ruled out the possibility that the function(s) that we have ascribed to F, U, and Y.p may actually be due to a subset of progeny of these cells. Although this is possible, it would not change our interpretation of how fate is specified in the eight B.a progeny. In addition, we have not ruled out the possibility that the 'activities' we have identified are mediated by multiple gene products or biochemical mechanisms. The different functions of a particular cell might be mediated by different genes, or a single function might be mediated by multiple processes. These issues, as well as the validity of the current model, may be addressed by genetic analysis of the system. Many of the ablations result in spicule abnormalities (for example, see Fig. 1; other data not shown), indicating that the system is amenable to mutant isolation and characterization.

pairs of cells generated in the B cell lineage of the C. ele gans male: aa, ap/pa, and pp. Our results suggest that multiple cell interactions (positional cues, their modulators, and lateral interactions) specify fate in the $\mathrm{B} \cdot \mathrm{a}(\mathrm{l} / \mathrm{r}) \mathrm{xx}$ pairs. Although aa fates $(\alpha / \beta)$ and ap/pa fates $(\varepsilon / \zeta)$ may result from one specification step, pp fates $(\gamma / \delta)$ require a twostep specification process. Fig. 15 illustrates a possible interpretation of how fate is specified by extracellular cues in the three $\mathrm{B} \cdot \mathrm{a}(\mathrm{l} / \mathrm{r}) \mathrm{xx}$ cell pairs.

aa pair (Fig. 15A): For the aa pair, we envision that the two cells of the pair interact to establish a pattern of one $\alpha$-like and one $\beta$-like cell by a lateral signalling mechanism (labelled (4); analogous to anchor cell specification in the C. elegans hermaphrodite; Seydoux and Greenwald, 1989). Positional cues overlay this interaction so it is skewed to always form the same anterior/posterior pattern. ap/pa/pp (and Y.p) act to generally promote posterior $(\beta)$ fate $(2,3)$, and $\mathrm{F}$ and $\mathrm{U}$ act to override this effect and locally promote $\alpha$ fate (1). The integration of these two types of cues could be entirely within the aa cells themselves, although the $\mathbf{a p} / \mathbf{p a} / \mathbf{p p}$ cells may also act to modulate or localize the $\mathrm{F} / \mathrm{U}$ signal.

ap/pa pairs (Fig. 15B): There are two identified positional cues that act in the ap/pa pairs. $\mathrm{F}$ and $\mathrm{U}$ act to promote $\varepsilon$ fate in both ap and pa (1), and the other B.a progeny act to promote $\zeta$ fates in pa (2). Since 'isolated' ap and pa cells adopt $\varepsilon$ and $\zeta$ fates, respectively, one part of F/U function may be to counteract the activity of the other B.a progeny. In addition, the B.a progeny cells may act to inhibit or localize the activity of F and $U$ (2). We cannot conclude whether the ap and pa cells interact actively.

pp pair (Fig. 15C): We propose two distinct steps in $\gamma / \delta$ fate specification, which may correspond to specification in pp cells, and in the pp cell daughters. In the first step, F/U promote anterior fate (1) and $\mathbf{a p} / \mathbf{p a} /(\mathbf{a a})$ promote posterior fate (2). The ap/pa/(aa) cells may also act to modulate or localize F/U activity at this step. The two pp cells may also interact with each other (4). Although the initial predilec- 
tion for $\gamma$ or $\delta$ fate may be specified in the first step, proper execution of the fates requires a second step. In the second step, $\mathrm{F}$ and $\mathrm{U}$ promote anterior fate (1), and Y.p promotes posterior fate (3). The ap and pa cells act to modulate or localize these two potential cues $(2,5)$. The role of the pa cells is to prevent Y.p activity from extending inappropriately to the anterior pp cell. Both the ap and pa cells act to localize $\mathrm{F} / \mathrm{U}$ activity to the anterior daughter (or granddaughters) of presumptive $\gamma$. We envision that these functions may be achieved by physically preventing the activities from reaching the inappropriate cells ('insulation'), although a variety of more active blocking or localization mechanisms are not excluded. $F$ and $U$ also appear to have a role in modulating cues produced by Y.p (not drawn in Fig.). This could be either direct or indirect. In the latter case, $\mathrm{F}$ and $\mathrm{U}$ might promote $\gamma$ fate to the exclusion of $\delta$ fate. Although the two steps of $\mathbf{p p}$ fate specification are distinct, some of their components may temporally or functionally overlap.

\section{Properties of the identified extracellular cues}

\section{The relationship among the cues}

Our model results in part from interpretation of lineages observed in multiply ablated animals. These experiments can address the specific nature of an interaction. For example, with respect to the pp cell fates, the result of double Y.p pa ablation resembles that of single Y.p ablation. The order of action of these two cues depends on interpretation. Although the Y.p activity can be interpreted to act before the pa activity, we prefer the simpler interpretation that pa is a negative modulator of Y.p activity. This interpretation places the activity of Y.p after, or concurrent with, the activity of the pa cells, and does not require that the pa cells be biochemically distinct from the ap cells or from the other B.a progeny.

The activities produced by F/U and the B.a progeny may act in parallel. This can be illustrated in the pp pair, where the lineages in $\mathrm{F}^{-} \mathrm{U}^{-} \mathbf{a p}^{-} \mathbf{p} \mathbf{a}^{-}\left(\mathbf{a a}^{-}\right)$animals are distinct from those seen in either single $\mathrm{F}^{-} \mathrm{U}^{-}$or $\mathbf{a p}^{-} \mathbf{p a}^{-}\left(\mathbf{a a}^{-}\right)$animals. Specifically, ablation of $\mathrm{F} / \mathrm{U}$ results in truncated lineages from presumptive $\gamma$, and ablation of ap/pa/(aa) results in abnormal proliferative lineages for both presumptive $\gamma$ and $\delta$. The double $\mathrm{F} / \mathrm{U}$ ap/pa/(aa) ablation results in abnormal lineages less extreme than in either of the single ablations. The abnormal proliferation is not apparent, but the cells generally exhibit more 'anterior-like' fates than in F/U ablations, and the fate of presumptive $\delta$ cells can be disrupted. If the $\mathrm{F} / \mathrm{U}$ cue and ap/pa/(aa) cue acted in a linear pathway, we would expect the effect produced by one ablation to be epistatic to the other, as in Y.p $\mathbf{p}^{-} \mathbf{a p}^{-}$animals. If the activities acted independently but at distinct steps, or on different cells, we might expect an additive effect in the doubly ablated animals. Since the double ablation more closely approximates to normal patterning than either single ablation, it suggests the activities may act in parallel and antagonistically on the same process (for example, see Kenyon, 1986).

\section{Active extracellular cues in the specification of B.a $(\mathrm{l} / \mathrm{r}) \times \mathrm{x}$ fates}

Although many of the identified 'activities' may actually represent multiple biochemical products, it is useful to establish the minimum number of active products proposed by the model. We infer that a particular cue is active if the following two criteria are met: (1) ablation of the cell(s) that provides it results in fate disruption, and (2) double ablation experiments indicate that it can act independently of other cues. Of the five distinct interactions that specifiy fate in the B.a( $(1 / \mathrm{r}) \mathrm{xx}$ cells, we propose that at least four are active: cues from F/U, B.a progeny, Y.p, and lateral interactions (Fig. 15). (1) The activity of the F/U cue is suggested by the parallel function of $\mathrm{F} / \mathrm{U}$ and $\mathrm{B}$.a progeny in the aa and pp pairs, by its ability to promote $\varepsilon$ fate in pa cells, and by its ability to promote the abnormal proliferative lineages in pp cells. (2) The activity of the B.a progeny cue is suggested by the parallel function of $F / U$ and B.a progeny in the aa and pp pairs. In the ap/pa pair, only the modulatory function of the other B.a cells may normally be required. (3) The activity of the Y.p cue is suggested by its interaction with other activities (e.g., F/U), and by its ability to promote the pattern of $\mathbf{p p}$ cells in $\mathrm{F}^{-} \mathrm{U}^{-} \mathbf{a p}^{-} \mathbf{p a}^{-}$ $\left(\mathbf{a a}^{-}\right)$animals. (4) A lateral interaction is suggested in the aa cells in the patterning of fates in $\mathrm{F}^{-} \mathrm{U}^{-} \mathrm{Y} \cdot \mathrm{p}^{-} \mathbf{a p}^{-} \mathbf{p a}^{-} \mathbf{p} \mathbf{p}^{-}$ animals. (5) The role of the pa cells in promoting $\gamma$ fate is not independent of Y.p. Thus it might not represent an active process.

\section{Redundancy of the extracellular cues}

Our ablation experiments have revealed three instances of redundancy in extracellular cues. $F$ and $U$ are embryonic sister cells, and despite different lineages, they produce many common progeny types, including similar neurons (the EF and DX male specific neurons) and cells that play a role in the death of neighboring cells (Sulston et al., 1980). $\mathrm{F}$ and $\mathrm{U}$ behave similarly in their interactions with the B.a( $1 / \mathrm{r}) \mathrm{xx}$ cells, thus in terms of ' $\mathrm{F} / \mathrm{U}$ activity' we consider them to be duplicate cells with identical function.

The B.a progeny sets provide the second example of redundancy. It involves a relatively large but specifically characterized set of cells that are present (but not essential) as a group. Like F and U, they are lineally related. Although these cells share many characteristics, distinct differences in $\mathrm{B} . \mathrm{a}(\mathrm{l} / \mathrm{r}) \mathrm{xx}$ precursors and in terminal fates are evident during development of B.a. The redundancy is best seen in the aa pair, where any pair of the six other B.a cells is sufficient to specify $\beta$ fate. However, the 'B.a progeny' cue acts distinctly on each of the three cell pairs. Any pair of B.a( $(1 / \mathrm{r}) \mathrm{xx}$ cells is not always sufficient to promote posterior fate in the pa cells, and the six cells are not equivalent in their action on the pp pair. We envision that the B.a progeny may serve more than one role (for instance, an active role plus a passive, 'insulating' role). Thus this redundancy may reflect redundancy of position (neighboring cells are present, regardless of fate) as well as redundancy of a common positional cue. The relative requirement for, or responsiveness to, these two distinct functions may differ among the three types of cell pairs.

The cues involved in aa anterior-posterior patterning are distinct. Ablation of $\mathrm{F} / \mathrm{U}$, for instance, results in a different effect on aa fate than ablation of Y.p or ap/pa/pp (compare Fig. 6 and Table 2 with Fig. 9 and Table 3). Therefore, the redundancy of this system is not a common activity 
Table 7. Summary of cells that provide positional cues and the fates they promote

\begin{tabular}{c|ccccccc}
\hline & \multicolumn{7}{c}{ Promote fate } \\
\cline { 2 - 7 } Cell(s) & $\Gamma_{\alpha}$ & aa & $\beta$ & & \multicolumn{7}{c}{ pp } & \multicolumn{2}{c}{ ap/pa } \\
F/U & ++ & - & ++ & - & + & - \\
Y.p & - & + - & - & ++ & - & - \\
pa & - & - & ++ & - & - & $\times$ \\
ap/pa/(aa) & $\times \dagger$ & $\times \dagger$ & ++ & ++ & $\times$ & $\times$ \\
ap/pa/pp & - & ++ & $\times$ & $\times$ & $\times$ & $\times$ \\
aa/ap/pp & $\times$ & $\times$ & $\times$ & $\times$ & $\times$ & ++
\end{tabular}

The role of a cell in promotion of a particular fate is inferred from the effects observed following cell ablation. ++ , strongly promotes fate. + , weakly promotes fate. $+/-$, may play a minor role in promoting fate. - , does not play a role in promoting fate. $\mathrm{x}$, cell is absent. $\dagger$ If they are present, the aa cells are not affected.

shared by the three components, but rather different pieces of information about anterior-posterior position. For instance, if ap/pa/pp cells are present, either F/U (anterior cue) or Y.p (posterior cue) provides sufficient information about the environment for proper migration. The ' 2 of 3' aspect of this system may reflect a precise sensitivity of the cells to the positional cues. Alternatively, it may result because the ap/pa/pp cells modulate or localize the $\mathrm{F} / \mathrm{U}$ and Y.p cues. Specifically, if only one of F/U or Y.p is present, then the modulatory role of the $\mathbf{a p} / \mathbf{p a} / \mathbf{p p}$ cells is required to establish a gradient of $F / U$ or Y.p cue. If both F/U and Y.p are present, the ap/pa/pp activity is not necessary because the F/U 'anterior' and Y.p 'posterior' cues are distinct, and can establish asymmetry in the aa environment.

\section{The permissive nature of the extracellular cues}

In general, removal of several distinct cells or groups of cells can disrupt specific B.a progeny fates (Table 7). For instance, disruption of presumptive $\gamma$ lineages results from ablation of F/U, pa, or ap/pa/(aa) (see Figs 6, 9; Tables 2, $5)$. Likewise, presumptive $\delta$ lineages are disrupted by ablation of either Y.p or ap/pa/(aa). All of these cues are not entirely necessary for a specific fate, however. For instance, $2 / 5$ pp cells isolated from all identified positional cues produced $\gamma$-like lineages (Table 1L.2). pp cells thus retain the potential to adopt $\gamma$ fate. Nevertheless, the integration of multiple extracellular cues, combined with the cells' inherent potential, is required for proper, consistent execution of pp cell fate.

Is any particular cue necessary and/or sufficient to specify any given fate? Y.p is necessary, though not sufficient, for $\delta$ fate. F/U is necessary, and possibly sufficient, for $\varepsilon$ fate in pa, though clearly not in ap. No cells or combination of cells is entirely necessary or sufficient for $\alpha, \beta$, and $\gamma$ fates. We thus consider most of the interactions in terms of 'promotion' of one fate choice over another.
Table 8. Differentiated fates of $B$ progeny

\begin{tabular}{ccccc}
\hline & \multicolumn{4}{c}{ Differentiated Fates } \\
\cline { 2 - 5 } Precursor & N & N.Sup & Proct & Death \\
\hline$\alpha$ & & 2 & 2 & \\
$\beta$ & 2 & 4 & & 1 \\
$\gamma$ & & 2 & 3 & 1 \\
$\delta$ & & & 2 & \\
$\varepsilon$ & & & 5 & $1+(1) \dagger$ \\
$\zeta$ & 3 & 2 & &
\end{tabular}

N, neuron; N. Sup, neuronal support cell (socket or sheath cell); Proct, proctodeal cell; Death, cell that undergoes programmed cell death. For example, a $\beta$ lineage produces 6 progeny: 2 neurons and 4 neuronal support cells ( 2 socket and 2 sheath cells). $†$ Each $\varepsilon$ lineage includes one invariant and one conditional death (either the left or the right cell will die, but not both). Thus combined, the $\varepsilon$ lineages produce a total of 3 cell deaths. Data of Sulston et al. (1980).

The differences of the responses from the three cell pairs suggest that the extracellular cues promote specific choices between neuroectoblast fates rather than promoting proliferation or the production of a specific differentiated cell type per se. For example, $\mathrm{F}$ and $\mathrm{U}$ act to increase proliferation in the case of $\mathbf{p p}$ and $\mathbf{a p} / \mathbf{p a}$ cells (promote $\gamma$ and $\varepsilon$ ), but decrease proliferation in the case of aa cells (promote $\alpha$ ) (see Fig. 2). Likewise, F and U do not appear to promote specific precursor or differentiated cell types. In intact animals, there are three general cell types in the progeny of B.a: neurons, neuronal support cells, and proctodeum (epidermis) (Sulston et al., 1980). However, neurons, for instance, arise at several positions in the lineage rather than from a single neuroblast precursor (Table 8). Even if one considers neurons and support cells as a common 'neuronal' type, $\beta$ and $\zeta$ are neuronal precursors, $\delta$ and $\varepsilon$ are proctodeal precursors, and $\alpha$ and $\gamma$ are 'mixed,' producing both neuronal and proctodeal progeny. In addition, ablation of $\mathrm{F}$ and $U$ disrupts the more neuronal lineage in the pp pair, but the more proctodeal lineage in the ap/pa pairs.

\section{Equivalence groups and specification of the pairs}

An equivalence group is a set of identical cells that are equally capable of executing a shared set of fates (Sulston and White, 1980; Kimble, 1981; Blair and Weisblat, 1984; Shankland and Weisblat, 1984; Doe and Goodman, 1985; Nishida and Satoh, 1989). These cells have equivalent developmental potential, and extracellular cues dictate the eventual fate. Are the aa, ap/pa, and pp pairs equivalence groups? The aa pair and the pp pair both exhibit natural variation in fate. Ablation experiments of Sulston and White (1980) indicate that the cells of the aa pair also exhibit a hierarchy of fates, with $\alpha 1^{\circ}$, and $\beta 2^{\circ}$. Thus, these cells likely represent an equivalence group in the strict sense. In contrast, similar experiments with the pp pair were unable 


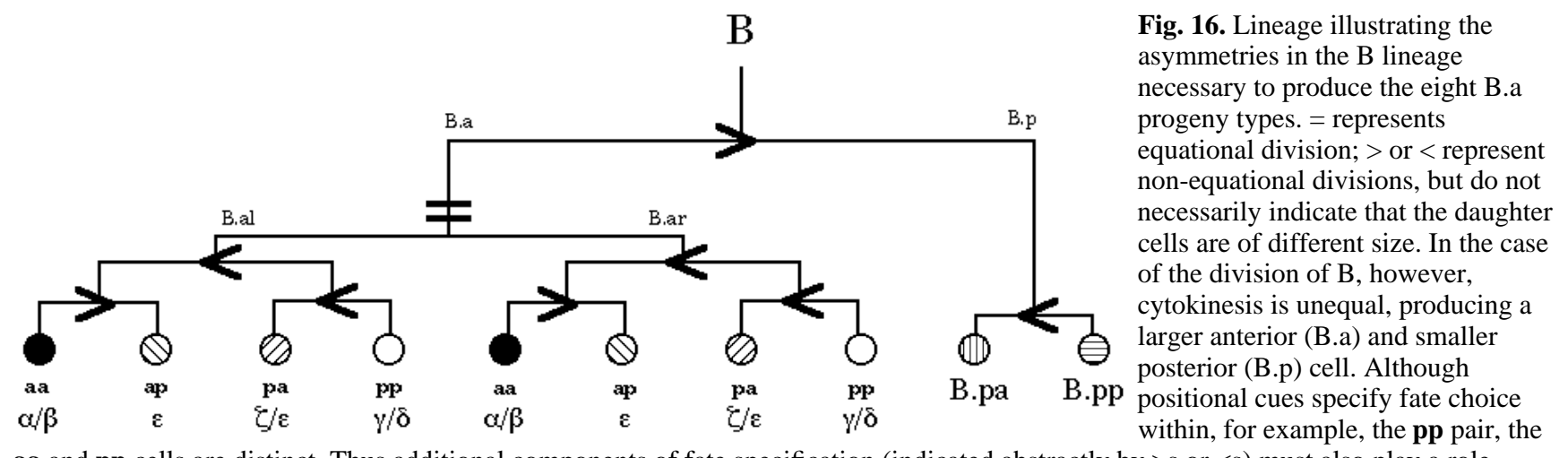

aa and pp cells are distinct. Thus additional components of fate specification (indicated abstractly by $>$ s or $<$ s) must also play a role. Since differences are apparent in the precursors of these cells (B.a(l/r)a and B.a(l/r)p), some of these components may be autonomous to the B.a(l/r) xx cells.

to establish a fate hierarchy. Although in the first step of pp fate specification the cells may be equivalent, our results indicate that there are two steps in the specification of $\gamma$ and $\delta$ fates. Thus it is impossible to interpret the fates in simple terms of $1^{\circ}$ and $2^{\circ}$ fates.

The ap/pa pairs exhibit replacement regulation, a characteristic often associated with cells in an equivalence group (e.g., Sulston and White, 1980). Specifically, pa cells will produce $\varepsilon$ lineages in the absence of the other B.a progeny. However, under experimental conditions the ap cells have never produced $\zeta$ lineages. Although both cells respond to positional cues, $\mathrm{F}$ and $\mathrm{U}$ are required to promote the transformation to $\varepsilon$ fate in pa, whereas the ap cells can produce normal $\varepsilon$ lineages in the absence of $F$ and $U$. Our experiments do not completely rule out the ability of ap to adopt $\zeta$ fate. Nevertheless, after isolation of the cells by removal of all identified positional cues, the ap cells adopt their normal $\varepsilon$ fate, and the pa cells the $\zeta$ fate. Thus, the ap and pa may not be functionally equivalent. pa may have the potential to adopt both $\varepsilon$ and $\zeta$ fates, whereas ap could be restricted to the $\varepsilon$ fate. If this is the case, then these cells represent an example of replacement regulation without equivalent potential.

What is the relationship among the three pairs? We propose that each $\mathrm{B} . \mathrm{a}(\mathrm{l} / \mathrm{r}) \mathrm{xx}$ cell is competent to make a particular choice of fate ( $\alpha$ versus $\beta, \gamma$ versus $\delta, \varepsilon$ versus $\zeta$ ), and this competence results from an earlier specification event. First, the cells of a given pair (e.g., aa) respond to specific cell ablations (e.g., Y.p ${ }^{-}$) with different intensity than the cells in the other pairs (e.g., pp). Second, the behaviors of aa, pa, ap, and pp cells in 'isolated' backgrounds are distinct (see Results, Section III). Third, in general there are no obvious examples of a cell of one pair that adopts the fate normally associated with another pair. Although some lineages share some superficial characteristics, we do not believe that any disrupted lineages ever represent transformation of fate potential from one pair to another. Since the three cell pairs appear to be different, distinct fate specification events may take place in the early progeny of B to distinguish, for instance, the aa pair from the pp pair (Fig. 16). These distinctions might be autonomously specified. Division of B.a establishes the left/right symmetry of the spicules, and produces two appar- ently identical daughters. This equational division produces two cells that each produce a set of four progeny. To obtain four distinct progeny types, both rounds of division must be asymmetric, i.e., give rise to different progeny types. Although, as yet unidentified cell interactions may be responsible for these distinctions, the difference in the timing of $\mathrm{B} . \mathrm{a}(\mathrm{l} / \mathrm{r}) \mathrm{p}$ division compared with $\mathrm{B} . \mathrm{a}(\mathrm{l} / \mathrm{r}) \mathrm{a}$ indicates that these precursors of the $\mathrm{B} \cdot \mathrm{a}(\mathrm{l} / \mathrm{r}) \mathrm{xx}$ cells already have distinct cell states.

\section{Signal integration: three general types of cell interactions}

We have demonstrated that the $\mathrm{B} \cdot \mathrm{a}(\mathrm{l} / \mathrm{r}) \mathrm{xx}$ cell fates are specified by three distinct types of cell interactions: (a) positional cues, (b) modulators of positional cues, and (c) lateral cues (Fig. 17). Positional cues are unidirectional, or at least the cells producing them are not responsive to direct feedback as a result of exposure to the cue (in contrast to lateral cues). Active 'signals' - so called inducers and inhibitors - represent positional cues. Modulators act to localize or otherwise modify the activity or effect of a positional cue. Their unique characteristic is that this function is dependent entirely on the presence of the positional

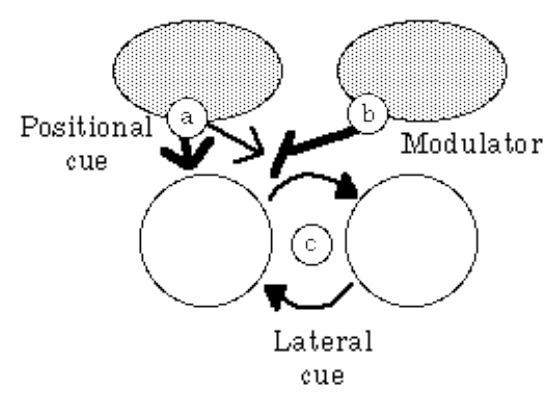

Fig. 17. Three general types of intercellular signals. (a) Positional cues: inducers, inhibitors. These cues provide unidirectional positional information. (b) Modulators: active or passive. Modulators act on positional cues. Their function is dependent on the presence of the positional cue. (c) Lateral signals. These signals act reciprocally among cells of equivalent potential, and include a feedback mechanism. See text for additional discussion. 
cue. Modulators can be active (e.g., production of an enzyme that degrades or modifies the positional cue) or passive (e.g., insulators that physically block another cell's access to the positional cue). Lateral cues are reciprocal (at least initially) between cells of equivalent potential, and include a feedback mechanism. Feedback can be inhibitory, and thus result in the amplification of a discrepancy between the cells (Seydoux and Greenwald, 1989; Heitzler and Simpson, 1991), or excitatory, and thus result in the amplification of a particular effect in both (all) cells. In general, complexity may arise from the fact that there may be multiple positional cues, all acting in parallel, as well as multiple modulators, and so on. In addition, the actual units of specification may be layered so that fates may result from a series of discrete specification steps.

In the $\mathrm{B} \cdot \mathrm{a}(1 / \mathrm{r}) \mathrm{xx}$ cells, we observe examples of cues that act in series as well as in concert at the same step of fate specification. The cues involved in the first and second steps of pp cell fate specification act in series. Modulators, in contrast, act at the same step as the activities they modulate. In addition, some activities (e.g., those produced by F/U and B.a progeny) may act in parallel and antagonistically on the same process, and thus act at the same step. Lateral interactions may also be concurrent with the positional cues in the B lineage. Since in both aa and pp cells all fates $(\alpha / \beta$ and $\gamma / \delta)$ are observed in animals with just a single cell of the pair present, lateral interactions are not necessary for any fate. Thus, in this case the normally precise pattern of fate is unlikely to result from the promotion of one fate (e.g. anterior) followed by lateral interactions to promote the other (e.g. posterior).

Although a single positional cue might be sufficient to specify fate distinctions, the integration of the three types of cues, combined with redundancy, may result in a more robust fate specification mechanism. The use of multiple signals is observed in several systems. For instance, Xeno pus mesoderm induction requires multiple positional cues from vegetal cells (reviewed by Kimelman et al., 1992) and the 'community effect' (Gurdon et al., 1984; Gurdon et al., 1993), a potential excitatory lateral interaction. Similarly, vulval induction in $C$. elegans hermaphrodites likely involves at least two positional cues and a lateral interaction (reviewed by Horvitz and Sternberg, 1991). In some systems one cue may predominate (for example, lateral signalling during anchor cell specification; Seydoux and Greenwald, 1989) and be both necessary and sufficient for a particular fate. However, technical constraints may also limit the characterization of the true complexity of fate specification in many systems. We expect that complex integration of these three types of cell interactions may be common in other tissues and organisms.

We thank Leon Avery, Eric Davidson, Scott Fraser, Andy Golden, Russell Hill, Linda Huang, Gregg Jongeward, Paul Kayne, Howard Lipshitz, and Anna Newman for comments on the manuscript, and Gladys Medina for technical assistance. CB1490 was provided by the Caenorhabditis Genetics Center. This research was supported by the Howard Hughes Medical Institute. H. M. C. was an NSF predoctoral fellow. P. W. S. is an investigator of HHMI.

\section{REFERENCES}

Avery, L. and Horvitz, H. R. (1987). A cell that dies during wild-type $C$. elegans development can function as a neuron in a ced-3 mutant. Cell $\mathbf{5 1}$, 1071-1078.

Blair, S. S. and Weisblat, D. A. (1984). Cell interactions in the developing epidermis of the leech Helobdella triserialis. Dev. Biol. 101, 318-325.

Bowerman, B, Tax, F. E., Thomas, J. H. and Priess, J. R. (1992). Cell interactions involved in development of the bilaterally symmetrical intestinal valve cells during embryogenesis in Caenorhabditis elegans. Development 116, 1113-1122.

Brenner, S. (1974). The genetics of Caenorhabditis elegans. Genetics 77, 71-94.

Chisholm, A. D. and Hodgkin, J. (1989). The mab-9 gene controls the fate of $\mathrm{B}$, the major male-specific blast cell in the tail region of Caenorhabditis elegans. Genes Dev. 33, 1413-1423.

Doe, C. Q. and Goodman, C. S. (1985). II. The role of cell interactions and cell lineage in the determination of neuronal precursor cells. Dev. Biol. 111, 206-219.

Goldstein, B. (1992). Induction of gut in Caenorhabditis elegans embryos. Nature 357, 255-257.

Greenwald, I. S., Sternberg, P. W. and Horvitz, H. R. (1983). The lin-12 locus specifies cell fates in Caenorhabditis elegans. Cell 34, 435-444.

Gurdon, J. B., Brennan, S., Fairman, S. and Mohun, T. J. (1984) Transcription of muscle-specific actin genes in early Xenopus development: Nuclear transplantation and cell dissociation. Cell 38, 691700 .

Gurdon, J. B., Tiller, E., Roberts, J. and Kato, K (1993) A community effect in muscle development. Curr. Biol. 3, 1-11.

Heitzler, P and Simpson, P. (1991). The choice of cell fate in the epidermis of Drosophila. Cell, 64, 1083-1092.

Hodgkin, J., Horvitz, H. R. and Brenner, S. (1979). Nondisjunction mutants of the nematode Caenorhabditis elegans. Genetics 91, 67-94

Horvitz, H. R., Sternberg, P. W., Greenwald, I. S., Fixsen, W. and Ellis, H. M. (1983). Mutations that affect neural cell lineages and cell fates during the development of the nematode Caenorhabditis elegans. Cold Spring Harbor Symp. Quant. Biol. 48, 453-463.

Horvitz, H. R. and Sternberg, P. W. (1991). Multiple intercellular signalling systems control the development of the $C$. elegans vulva. Nature 351, 535-541.

Kenyon, C. J. (1986) A gene involved in the development of the posterior body region of Caenorhabditis elegans. Cell 46, 477-487.

Kimble, J. and Hirsh, D. (1979). The postembryonic cell lineages of the hermaphrodite and male gonads in Caenorhabditis elegans. Dev. Biol. 70, 396-417.

Kimble, J. (1981). Lineage alterations after ablation of cells in the somatic gonad of Caenorhabditis elegans. Dev. Biol. 87, 286-300.

Kimelman, D., Christian, J. L. and Moon, R. T. (1992). Synergistic principles of development: overlapping patterning systems in Xenopus mesoderm induction. Development 116, 1-9.

Nishida H. and Satoh, N. (1989). Determination and regulation in the pigment cell linege of the ascidian embryo. Dev. Biol. 132, 355-367.

Priess, J. R. and Thomson, J. N. (1987). Cellular interactions in early Caenorhabditis elegans embryos. Cell 48, 241-250.

Schierenberg, E. (1987). Reversal of cellular polarity and early cell-cell interactions in the embryo of Caenorhabditis elegans. Dev. Biol. 122, 452-463.

Seydoux, G. and Greenwald, I. (1989). Cell autonomy of lin-12 function in a cell fate decision in C. elegans. Cell 57, 1237-1245.

Shankland, M. and Weisblat, D. A. (1984). Stepwise commitment of blast cell fates during the positional specification of the $\mathrm{O}$ and $\mathrm{P}$ cell lines in the leech embryo. Dev. Biol. 106, 326-342.

Sternberg, P. W. (1988). Lateral inhibition during vulval induction in Caenorhabditis elegans. Nature 335, 551-554.

Sternberg, P. W. and Horvitz, H. R. (1986). Pattern formation during vulval development in Caenorhabditis elegans. Cell 44, 761-772.

Sternberg, P. W. and Horvitz, H. R. (1988). lin-17 mutations of C. elegans disrupt asymmetric cell divisions. Dev. Biol. 130, 67-73.

Sulston, J. and Horvitz, H. R. (1977). Postembryonic cell lineages of the nematode Caenorhabditis elegans. Dev. Biol. 56, 110-156.

Sulston, J. E., Albertson, D. G. and Thomson, J. N. (1980). The Caenorhabditis elegans male: Postembryonic development of nongonadal structures. Dev. Biol. 78, 542-576.

Sulston, J. E. and Hodgkin, J. (1988). Methods In The Nematode 
Caenorhabditis elegans. (ed. W. Wood), pp. 587-606. Cold Spring Harbor Laboratory: Cold Spring Harbor, New York.

Sulston, J. E., Schierenberg, E., White, J. G. and Thomson, J. N. (1983).

The embryonic cell lineage of the nematode Caenorhabditis elegans. Dev. Biol. 100, 64-119.

Sulston, J. E. and White, J. G. (1980). Regulation and cell autonomy during postembryonic development of Caenorhabditis elegans. Dev. Biol. 78, 577-597.

Wood, W. B. (1991). Evidence from reversal of handedness in C. elegans for early cell interactions determining cell fates. Nature 349, 536-538.

(Accepted 10 March 1993) 